\title{
Streptomyces scabies 87-22 Contains a Coronafacic Acid-Like Biosynthetic Cluster That Contributes to Plant-Microbe Interactions
}

\author{
Dawn R. D. Bignell, ${ }^{1}$ Ryan F. Seipke, ${ }^{1}$ José C. Huguet-Tapia, ${ }^{1}$ Alan H. Chambers, ${ }^{1}$ Ronald J. Parry, ${ }^{2}$ and \\ Rosemary Loria ${ }^{1}$
}

${ }^{1}$ Department of Plant Pathology and Plant-Microbe Biology, Cornell University, Ithaca, NY 14853, U.S.A.; ${ }^{2}$ Department of Chemistry, Rice University, Houston 77005, U.S.A.

Submitted 6 August 2009. Accepted 17 October 2009.

\begin{abstract}
Plant-pathogenic Streptomyces spp. cause scab disease on economically important root and tuber crops, the most important of which is potato. Key virulence determinants produced by these species include the cellulose synthesis inhibitor, thaxtomin $A$, and the secreted Nec1 protein that is required for colonization of the plant host. Recently, the genome sequence of Streptomyces scabies 87-22 was completed, and a biosynthetic cluster was identified that is predicted to synthesize a novel compound similar to coronafacic acid (CFA), a component of the virulence-associated coronatine phytotoxin produced by the plant-pathogenic bacterium Pseudomonas syringae. Southern analysis indicated that the $c f a$-like cluster in $S$. scabies $87-22$ is likely conserved in other strains of $\mathbf{S}$. scabies but is absent from two other pathogenic streptomycetes, $S$. turgidiscabies and $S$. acidiscabies. Transcriptional analyses demonstrated that the cluster is expressed during plant-microbe interactions and that expression requires a transcriptional regulator embedded in the cluster as well as the bldA tRNA. A knockout strain of the biosynthetic cluster displayed a reduced virulence phenotype on tobacco seedlings compared with the wild-type strain. Thus, the $c f a$-like biosynthetic cluster is a newly discovered locus in $S$. scabies that contributes to host-pathogen interactions.
\end{abstract}

The ability to produce medically and agriculturally important secondary metabolites, including many antibiotic, antitumor, herbicidal, and immunosuppressive compounds, is a hallmark of gram-positive actinobacteria belonging to the genus Streptomyces (Berdy 2005). These filamentous bacteria are also renowned for their complex morphological life cycle, in which the organism grows as branched vegetative mycelia under conditions of nutrient abundance and then switches to the production of aerial hyphae and spores under conditions of nutrient limitation (Elliot et al. 2008). On the other hand, the capability of Streptomyces spp. to cause diseases of economically impor-

Corresponding author: D. R. D. Bignell; Telephone (+1) 607-255-9770; Fax (+1) 607-255-4471; E-mail: drb58@ cornell.edu

Current address of R. F. Seipke: School of Biological Sciences, University of East Anglia, Norwich Research Park, Norwich NR4 7TJ, U.K.

The nucleotide sequences described here are deposited in the EMBL database (accession number FN554889).

* The $\boldsymbol{e}$-Xtra logo stands for "electronic extra" and indicates that a supplementary table and a supplementary figure are published online. tant root and tuber crops is far less appreciated, primarily because only a small number of species possess this attribute. The three best-characterized plant-pathogenic species (Streptomyces scabies, $S$. turgidiscabies, and $S$. acidiscabies) cause common scab of potato, a disease that is characterized by round, raised, or pitted corky-like lesions that form on the surface of the tubers. These lesions affect the marketability of the potato crop, leading to significant economic losses in potatoproducing regions worldwide (Loria et al. 2006). All three pathogenic streptomycetes are neither tissue nor host specific; therefore, they can also induce scab symptoms on taproot crops such as carrot, radish, and beet, and can infect the fibrous roots of model plants such as Arabidopsis and tobacco, leading to root stunting, swelling, and necrosis (Loria et al. 2006). However, infection of the plant host is developmentally constrained in that only expanding plant tissue is susceptible.

A key virulence determinant in scab-causing streptomycetes is a family of phytotoxic secondary metabolites called the thaxtomins, of which thaxtomin $\mathrm{A}$ is the most predominant (King and Calhoun 2009). Thaxtomin A is a nitrated 2,5-diketopiperazine synthesized from phenylalanine and 4-nitro-Ltryptophan and is essential for scab disease development (Healy et al. 2000; Johnson et al. 2009; King and Calhoun 2009). It functions by inhibiting cellulose biosynthesis, a conserved process in higher plants, and it also stimulates plant cell $\mathrm{H}^{+}$and $\mathrm{Ca}^{2+}$ ion influx and induces programmed cell death (Loria et al. 2006). The biosynthesis of thaxtomin A requires the nonribosomal peptide synthetases TxtA and TxtB as well as a nitric oxide synthase (NOS/TxtD) and a cytochrome P450 monooxygenase, TxtC (Loria et al. 2008). The corresponding biosynthetic genes are highly conserved in S. scabies, S. acidiscabies, and $S$. turgidiscabies and have not been found in any non-plant-pathogenic Streptomyces spp. A regulatory gene, txtR, is embedded within the thaxtomin biosynthetic cluster and activates expression of the biosynthetic genes in response to cellobiose (Joshi et al. 2007b). Cellobiose and cellotriose, the smallest subunits of cellulose, both induce thaxtomin A production (Johnson et al. 2007) and may serve as a signal for the presence of expanding plant tissue, which is the site of action of thaxtomin A (Fry and Loria 2002; Scheible et al. 2003).

An additional virulence determinant that has been described in plant-pathogenic streptomycetes is a secreted necrogenic protein called Nec1. Nec1 has no homologues in the protein databases, is required for colonization of the plant host, and may function to suppress plant defense responses (Bukhalid and Loria 1997; Joshi et al. 2007a). Furthermore, a putative virulence gene, tom $A$, is conserved in the three pathogenic 
streptomycetes (Kers et al. 2005) and is homologous to saponinase-encoding genes, which are important for host-pathogen interactions in some plant-pathogenic fungi (Seipke and Loria 2008). Although a tomA deletion mutant did not show a reduced virulence phenotype compared with wild-type (WT) $S$. scabies, the conservation of this gene in pathogenic streptomycetes suggests a role for this gene in plant-microbe interactions (Seipke and Loria 2008). The necl, tomA, and thaxtomin biosynthetic genes are all present on a large, mobilizable pathogenicity island in S. turgidiscabies Car8, and the transfer of this island to recipient species is believed to be the mechanism in which new pathogenic Streptomyces spp. emerge in agricultural settings (Kers et al. 2005).

Recently, the $S$. scabies 87-22 genome sequence was completed, and analysis of the sequence revealed a number of additional genes and gene clusters that could potentially be involved in host-pathogen interactions. Here, we describe the identification and characterization of a newly discovered secondary metabolite biosynthetic cluster that is predicted to synthesize a compound similar to coronafacic acid (CFA), a component of the coronatine (COR) phytotoxin produced by several pathovars of the plant pathogen Pseudomonas syringae. COR is required for the full virulence phenotype of $P$. syringae (Bender et al. 1999a and b) and a putative $c f a$ biosynthetic cluster in a second plant pathogen, Pectobacterium atrosepticum (formerly Erwinia carotovora subsp. atroseptica), is important for the pathogenic phenotype of that organism (Bell et al. 2004). Through expression analyses and mutational studies, we demonstrate here that the $S$. scabies CFA-like molecule also plays a role in plant-microbe interactions during the infection process.

\section{RESULTS}

Identification of a putative virulence-associated secondary metabolite biosynthetic cluster in S. scabies.

While analyzing the $S$. scabies 87-22 genome, we identified a cluster of genes that appeared to encode proteins for the synthesis of a polyketide-like secondary metabolite. The cluster is predicted to be approximately $31 \mathrm{~kb}$ in size and consists of 15 coding sequences based on gene organization, homology searches and transcriptional analyses (Fig. 1A; Table 1). Thirteen of these genes are oriented in the same direction and many of them are predicted to overlap, which suggests that they are translationally coupled. Analysis of the published genome sequences for the nonpathogenic streptomycetes S. coelicolor (Bentley et al. 2002), S. avermitilis (Ikeda et al. 2003), and S. griseus (Ohnishi et al. 2008), as well as the unpublished genome sequences (available in the public database) for five additional nonpathogenic Streptomyces spp. (S. sviceus, S. clavuligerus, S. pristinaespiralis, Streptomyces sp. strain Mg1, and Streptomyces sp. strain SPB74), indicated that this $S$. scabies putative secondary metabolite cluster is not conserved in any of these species. However, the cluster is highly similar in structure and organization to the $c f a$ biosynthetic cluster found in several pathovars of the plant-pathogenic bacterium $P$. syringae, as well as a putative $c f a$ biosynthetic cluster recently identified in another plant pathogen, Pectobacterium atrosepticum (Fig. $1 \mathrm{~B}$ and $\mathrm{C}$ ). In $P$. syringae, CFA is an intermediate in the biosynthesis of the COR phytotoxin (Fig. 1D), which is an important virulence determinant in that organism (Bender et al. 1999a and b), and mutational studies demonstrated that the putative $c f a$ biosynthetic cluster contributes to virulence in Pectobacterium atrosepticum (Bell et al. 2004). Given the conservation of this biosynthetic cluster in plant-pathogenic bacteria, together with the published mutational studies in $P$. syringae and Pectobacterium atrosepticum, we hypothesized that the $S$. scabies biosynthetic cluster is also important for plant-microbe interactions and represents a newly discovered virulence determinant in that organism.

\section{Bioinformatics analyses predict that the $S$. scabies secondary metabolite biosynthetic cluster produces a novel CFA-like molecule.}

Nine of the genes from the $S$. scabies biosynthetic cluster encode proteins that are homologous to those encoded in the cfa clusters from $P$. syringae pv. tomato and Pectobacterium atrosepticum (Table 1). The cfal-5 genes encode enzymes believed to be responsible for synthesis of the CFA intermediate, 2-carboxy-2-cyclopentenone (CPC), from $\alpha$-ketoglutarate and malonyl-CoA (Rangaswamy et al. 1998). The $c f a 6$ and $c f a 7$ genes encode large multifunctional type-I polyketide synthase (PKS) proteins required for synthesis of the CFA backbone (Table 1). Phylogenetic analysis indicated that the acyltransferase (AT) domains (AT0, AT1, and AT2) from the S. scabies $\mathrm{Cfa} 6$ and $\mathrm{Cfa} 7$ proteins are most closely related to the corresponding domains from the $P$. syringae and Pectobacterium atrosepticum $\mathrm{Cfa} 6$ and $\mathrm{Cfa} 7$ proteins (Supplementary Fig. S1); because AT domains specify the starter and extender units in polyketide biosynthesis (Katz 2009), this suggests that the same starter and extender units are used in all three organisms. Interestingly, the enoyl reductase (ER2) domain in the $S$. scabies $\mathrm{Cfa} 7$ protein is not present in the corresponding proteins in $P$. syringae pv. tomato and Pectobacterium atrosepticum (Fig. 2A). Analysis of the domain sequence revealed the presence of the conserved NADP $(\mathrm{H})$ binding motif LXHX(G/A) XGGVG, which is characteristic of these domains (Donadio and Katz 1992). This suggests that the ER2 domain in the $S$. scabies $\mathrm{Cfa} 7$ protein is active and that a double bond that is normally present in the $P$. syringae CFA molecule would be reduced in the $S$. scabies product (Fig. 2B).

All three biosynthetic clusters contain a $c f l$ (coronafacate ligase) gene that is located at the beginning of the $c f a$ cluster in P. syringae and Pectobacterium atrosepticum (Fig. 1B and C) and is present towards the end of the S. scabies biosynthetic cluster (Fig. 1A). Cfl in P. syringae is thought to be required for ligation of CFA to coronamic acid (CMA), an ethylcyclopropyl amino acid derived from isoleucine, to give the COR phytotoxin (Fig. 1D) (Bender et al. 1999b). Interestingly, $S$. scabies is not predicted to synthesize COR because the biosynthetic genes for CMA are not present in the genome; a similar situation has been reported for Pectobacterium atrosepticum (Bell et al. 2004). However, the substrate specificity of the $P$. syringae $\mathrm{Cfl}$ protein is believed to be relaxed because a variety of coronafacoyl-amino acid conjugates have been isolated, including CFA-Ile, CFA-Val, CFA-Ser, and CFA-Thr (Bender et al. 1999b). Therefore, it is conceivable that the Cfl proteins in Pectobacterium atrosepticum and S. scabies might generate CFA-amino acid conjugates similar to those observed in $P$. syringae. Alternatively (or in addition), the Cfl orthologues may play a role in polyketide biosynthesis as reported for the $P$. syringae Cfl (Rangaswamy et al. 1997).

Six genes were identified in the $S$. scabies biosynthetic cluster that have no homologues in the P. syringae and Pectobacterium atrosepticum cfa clusters (Fig. 1A, B, and C). One gene, scab79711, encodes a putative 3-hydroxybutyryl-CoA dehydrogenase (Table 1) that might function to reduce acetoacetyl-CoA to 3-hydroxybutyryl-CoA, an intermediate in crotonyl-CoA biosynthesis (Chan et al. 2009). Crotonyl-CoA, in turn, is a substrate for the crotonyl-CoA carboxylase/reductase (CCR) enzyme (encoded by $c f a 8$ ) (Table 1) that catalyzes the direct conversion of crotonyl-CoA to ethylmalony-CoA (Chan et al. 2009). Genes for both CCR and 3-hydroxybutyryl-CoA dehy- 
drogenase have been identified in the concanamycin A, elaiophylin, indanomycin, and lasalocid antibiotic biosynthetic clusters; the inclusion of such genes in secondary metabolite biosynthetic clusters may serve as a strategy for ensuring that sufficient ethylmalonyl-CoA is available for polyketide biosynthesis (Smith et al. 2008; Chan et al. 2009). Another gene, scab79691, encodes a putative P450 monooxygenase that might play a role in post-PKS tailoring of the polyketide product. Scab79691 contains the conserved heme-binding cysteine residue as well as the EXXR motif, which forms a charge pair in the K-helix of P450s (Zhao and Waterman 2007). Two other genes, scab79681 and scab79721, encoding a putative oxidoreductase and a short- chain dehydrogenase/reductase, respectively, might also play a role in modification of the $S$. scabies polyketide molecule.

The scab79591 gene (Fig. 1A; Table 1) encodes a 266amino-acid protein that shows highest similarity to members of a novel family of Streptomyces transcriptional regulators that are typically associated with antibiotic biosynthetic clusters. Members of this family are characterized by the presence of an N-terminal PAS fold-like motif and a C-terminal DNAbinding domain of the LuxR family. The PAS fold is found in cytoplasmic proteins in archaea, bacteria, and eukarya; it has a conserved structure despite having low sequence conservation across different family members (Hefti et al. 2004); and it
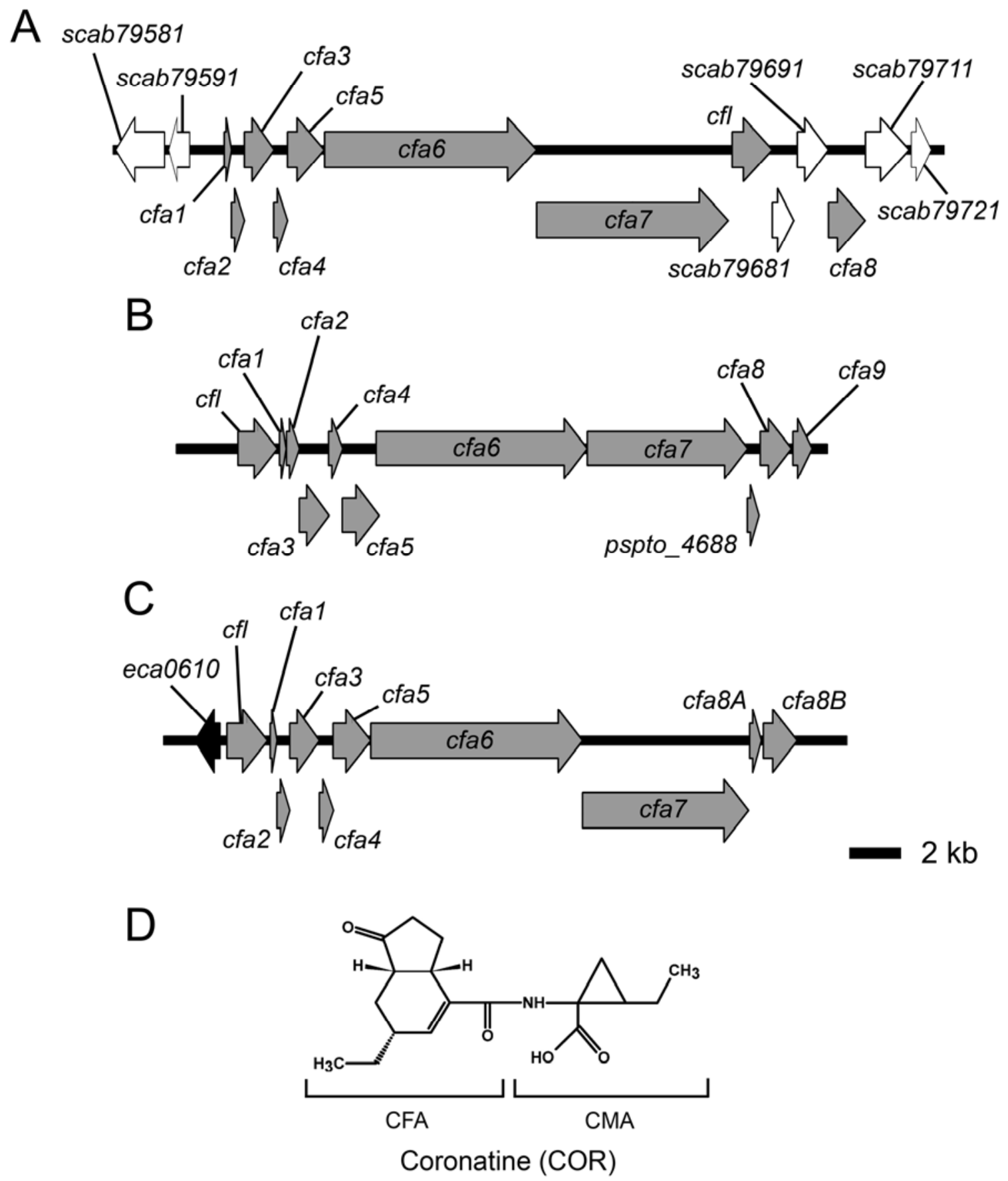

Fig. 1. Organization of A, the cfa-like biosynthetic gene cluster from Streptomyces scabies 87-22; B, the cfa biosynthetic cluster from Pseudomonas syringae pv. tomato DC3000; and C, the putative cfa biosynthetic cluster from Pectobacterium atrosepticum SCRI1043. Gray block arrows in all three clusters represent known or predicted biosynthetic genes, the black arrow in the $P$. atrosepticum cluster depicts a predicted regulatory gene, and the white arrows represent genes that are unique to the $S$. scabies cluster. The scale bar ( $2 \mathrm{~kb}$ ) applies to A, B, and C. D, Structure of the Pseudomonas syringae coronatine (COR) phytotoxin consisting of coronafacic acid (CFA) linked to coronamic acid (CMA). 
functions as a sensor of oxygen, redox potential, cellular energy levels, light, or small ligands (Taylor and Zhulin 1999). Immediately downstream of $s c a b 79591$ is a gene, scab79581 (Fig. 1A; Table 1), which encodes a 637-amino-acid protein showing low sequence similarity with other proteins in the database. BlastP analysis indicated that it is $25 \%$ identical and $39 \%$ similar to a UBA/ThiF-type NAD/FAD-binding fold protein from Nitrosospira multiformis (Table 1). The function of Scab79581 in the $S$. scabies biosynthetic cluster is not known.

Taken together, the in silico analyses indicate that the $S$. scabies polyketide biosynthetic cluster likely produces a compound that is structurally similar but not identical to CFA from P. syringae, and that the compound is likely novel in structure.

\section{The type-I PKS genes from the $c f a$-like cluster are conserved in strains of $S$. scabies but are absent from $S$. turgidiscabies and $S$. acidiscabies.}

The known virulence genes for thaxtomin A biosynthesis and for $\mathrm{Nec} 1$ as well as the putative virulence gene, tomA, are all highly conserved among strains of S. scabies, S. acidiscabies, and $S$. turgidiscabies. It was conceivable that the $S$. scabies polyketide biosynthetic cluster (herein referred to as the $c f a$-like cluster) might also be conserved among these pathogenic species; therefore, Southern analysis was performed to detect the $c f a 6$ and $c f a 7$ type-I PKS genes in each of the species. The strains for each species that were analyzed for the $c f a$-like cluster are listed in Table 2; all, with the exception of S. scabies 9616 and $S$. acidiscabies $98-48$, were deemed to be pathogenic using a radish seedling bioassay that mainly detects thaxtomin A production (Table 2). Surprisingly, none of the $S$. acidiscabies or $S$. turgidiscabies genomic DNA samples hybridized with either the $c f a 6$ - or $c f a 7$-specific probes (Table 2). On the other hand, both probes hybridized with DNA samples from most of the $S$. scabies strains, which were isolated from a variety of different geographical locations (Table 2). Interestingly, those $S$. scabies strains that were found to contain both $c f a 6$ and $c f a 7$ all belong to group 1 S. scabies whereas those that did not (e.g., strains 8904, 96-01, and 96-08) belong to group 2 S. scabies. These two groups differ by a single nucleotide in the $\gamma$-variable region of the $16 \mathrm{~S}$ ribosomal DNA gene (Bukhalid et al. 2002).
The $S$. scabies $c f a$-like cluster is expressed as two messenger RNA transcripts under thaxtomin-inducing conditions.

In light of the fact that newly discovered natural product biosynthetic clusters can be transcriptionally silent in the host organism under laboratory growth conditions (Challis 2008), we wanted to determine whether the $c f a$-like biosynthetic genes are expressed in $S$. scabies. RNA was isolated from $S$. scabies 87-22 mycelia harvested from trypticase soy broth (TSB), oat bran broth (OBB), and thaxtomin-defined medium with cellobiose (TDM-C) liquid cultures and was subjected to reverse-transcriptase polymerase chain reaction (RT-PCR) analysis. Transcription of the $c f a$-like cluster was not detected in the TSB cultures but expression did occur when $S$. scabies was grown in OBB and TDM-C (not shown); these latter two media also support the production of thaxtomin A (Johnson et al. 2007). We further characterized the expression of the $c f a$ like cluster by performing RT-PCR to evaluate whether the genes in the cluster are co-transcribed. In total, 10 products were amplified from cDNA template using PCR primers that were designed to amplify the junction regions between at least two genes in the cluster; no such products were detected when no RT (NRT) control reactions were performed (Fig. 3A and B). This indicates that the $c f a 1-s c a b 79721$ genes are expressed as a single approximately $27-\mathrm{kb}$ transcriptional unit (Fig. 3A). A second approximately $3-\mathrm{kb}$ transcription unit was also identified that consists of the putative regulatory gene, scab79591, as well as the $s c a b 79581$ coding sequence; both of these genes are oriented in the opposite direction to the cfal-scab79721 genes (Fig. 3A and B).

\section{Transcription of the $c f a$-like genes occurs during plant-microbe interactions.}

We predicted that, if the $c f a$-like biosynthetic cluster is important for pathogenicity, then the genes should be expressed when the pathogen is interacting with the plant host. We utilized a green fluorescent protein (GFP) promoter reporter system in order to test this hypothesis. The promoter region for cfal, which drives expression of the large, approximately 27$\mathrm{kb}$ transcript (Fig. 3A), was cloned upstream of a promoterless

Table 1. Predicted function of proteins encoded by the Streptomyces scabies $87-22$ cfa-like cluster and percent identity and similarity to homologous proteins from Pseudomonas syringae pv. tomato DC3000 and Pectobacterium atrosepticum SCRI1043

\begin{tabular}{|c|c|c|c|c|c|}
\hline \multirow[b]{2}{*}{ S. scabies gene } & \multirow[b]{2}{*}{$\mathbf{G}+\mathbf{C}(\%)$} & \multirow[b]{2}{*}{ Predicted protein product $^{\mathrm{a}}$} & \multirow[b]{2}{*}{ Predicted function $^{b}$} & \multicolumn{2}{|c|}{$\begin{array}{c}\text { Homologue, } \\
\text { identity/similarity }(\%)\end{array}$} \\
\hline & & & & DC3000 & SCRI1043 \\
\hline scab79581 & 74 & $\begin{array}{l}\text { UBA/THIF-type NAD/FAD binding fold } \\
\text { protein }\end{array}$ & Unknown & & \\
\hline scab79591 & 71 & Transcriptional regulator & Gene regulation & $\ldots$ & $\ldots$ \\
\hline scab79601; cfal & 60 & Acyl carrier protein $(\mathrm{ACP})$ & Biosynthesis of starter unit CPC & Cfa1, 59/73 & Cfa1, 61/74 \\
\hline scab79611; cfa2 & 62 & Type-II fatty acid dehydratase (DH) & Biosynthesis of starter unit CPC & $\mathrm{Cfa} 2,67 / 81$ & $\mathrm{Cfa} 2,67 / 84$ \\
\hline scab79621; cfa3 & 73 & Type-II $\beta$-ketoacyl synthase (KS) & Biosynthesis of starter unit CPC & $\mathrm{Cfa} 3,60 / 74$ & $\mathrm{Cfa} 3,61 / 74$ \\
\hline scab79631; cfa4 & 71 & Unknown & Biosynthesis of starter unit CPC & Cfa4, 53/66 & $\mathrm{Cfa} 4,52 / 69$ \\
\hline scab79641; cfa5 & 71 & Acyl-CoA ligase & Biosynthesis of starter unit CPC & Cfa5, 52/68 & Cfa5, 53/68 \\
\hline scab79651; cfa6 & 75 & $\begin{array}{l}\text { Type-I PKS loading module (AT0-ACP0) + } \\
\text { module } 1 \text { (KS1-AT1-DH1-ER1-KR1-ACP1) }\end{array}$ & Biosynthesis of CFA polyketide backbone & Cfa6, 52/64 & Cf6, 54/68 \\
\hline$s c a b 79661 ; c f a 7$ & 75 & $\begin{array}{l}\text { Type-I PKS module } 2 \text { (KS2-AT2-DH2-ER2- } \\
\text { KR2-ACP2) }\end{array}$ & Biosynthesis of CFA polyketide backbone & $\mathrm{Cfa} 7,56 / 67$ & Cf7, 52/66 \\
\hline scab79671; cfl & 72 & Acyl-CoA ligase & Generation of CFA-amino acid conjugates & Cfl, $40 / 59$ & Cfl, 36/58 \\
\hline scab79681 & 70 & Oxidoreductase & Modification of CFA backbone & $\ldots$ & $\ldots$ \\
\hline scab79691 & 69 & Cytochrome P450 monooxygenase & Modification of CFA backbone & .. & $\ldots$ \\
\hline scab79701; cfa8 & 69 & Crotonyl-CoA carboxylase/reductase (CCR) & $\begin{array}{l}\text { Biosynthesis of ethylmalonyl-CoA } \\
\text { extender unit }\end{array}$ & $\mathrm{Cfa} 8,36 / 52$ & $\mathrm{Cfa} 8 \mathrm{~b}, 35 / 52$ \\
\hline scab79711 & 72 & Hydroxybutyryl-CoA dehydrogenase & $\begin{array}{l}\text { Biosynthesis of ethylmalonyl-CoA } \\
\text { extender unit }\end{array}$ & & \\
\hline scab79721 & 69 & Short chain dehydrogenase/reductase & Modification of CFA backbone & $\ldots$ & $\ldots$ \\
\hline
\end{tabular}

${ }^{a}$ AT, acyltransferase; ER, enoylreductase; KR, ketoreductase; TE, thioesterase.

${ }^{\mathrm{b}} \mathrm{CPC}, 2$-carboxy-2-cyclopentenone. 
egfp gene, and promoter activity was assessed by visualizing fluorescence during colonization of plant roots. We were easily able to detect fluorescing mycelia from the $c f a l$ promoter reporter strain when it was colonizing the surface of tobacco seedling roots (Fig. 4). The observed fluorescence was well above any background fluorescence observed with a promoterless egfp control strain but was generally not as intense as that observed with the positive control strain where egfp expression was driven by the strong, constitutive promoter, ermEp* (Bibb et al. 1994). Similar results were observed when the GFP reporter strains were colonizing radish and Arabidopsis seedling roots (not shown). Furthermore, when the GFP reporter strains were incubated in the plant growth medium without tobacco plant material, only the positive control strain displayed significant fluorescence (not shown). Given that expression of the approximately 27-kb cfa-like messenger (m)RNA requires transcription of the scab79591 regulatory gene (discussed below), these results indicate that the two promoter regions driving expression of the $c f a$-like cluster are both active in planta.

\section{Expression of the $c f a$-like biosynthetic genes} is dependent on Scab79591 and on the bldA tRNA.

The location of the scab79591 regulatory gene next to the $c f a$-like biosynthetic genes (Fig. 1A) suggested that the corresponding protein product may function as a pathway-specific regulator for the biosynthetic cluster. Therefore, we made a knockout (KO) strain of scab79591 by replacing the coding sequence with a [hyg+oriT] disruption cassette. Four mutant iso- lates were recovered and were each verified by PCR and Southern analysis (data not shown). RT-PCR analysis of two of these mutant isolates, $\Delta s c a b 79591$ 22-3 (not shown) and $\Delta s c a b 79591$ 32-2 (Fig. 5A), indicated that expression of $c f a 5$, $c f a 6$, and $c f l$ is significantly reduced in these strains compared with the WT. PCR products for these genes were barely visible after 28 cycles (Fig. 5A) and were slightly more visible when the number of PCR cycles was increased to 30 (not shown). On the other hand, expression of scab79581, which is co-transcribed with scab79591 (Fig. 3A and B), was not affected in the $\Delta s c a b 79591$ mutants (Fig. 5A). We also examined $c f a$ gene expression in a strain where scab79591 was heterologously overexpressed using the ermEp* promoter. Overexpression of scab79591 resulted in enhanced expression of $c f a 5, c f a 6$, and $c f l$, whereas expression of scab79581 was unaffected (Fig. 5A). These results indicate that Scab79591 activates expression of the approximately 27-kb transcript containing cfal-scab79721 but appears to have no effect on the expression of the approximately 3-kb transcript containing scab79581 and scab79591.

Analysis of the scab79591 coding sequence indicated that it contains a TTA codon that corresponds to Leu81 in the 266amino-acid Scab79591 protein. TTA codons are rare in the GC-rich DNA of Streptomyces spp. (Wright and Bibb 1992) and are often found in genes associated with secondary metabolite biosynthetic clusters as well as genes that are involved in morphological development (Chater and Chandra 2008). The efficient translation of this codon often requires the bldA tRNA as mutants of bldA are typically defective in aerial hyphae formation as well as the ability to produce antibiotics (Lawlor et

\section{A Pseudomonas syringae $\mathrm{Cfa} 7$}

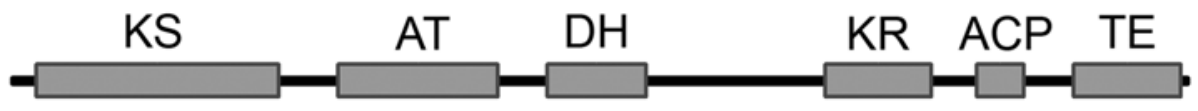

\section{Pectobacterium atrosepticum $\mathrm{Cfa} 7$}

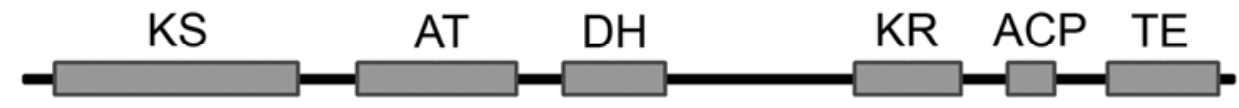

\section{Streptomyces scabies Cfa7}

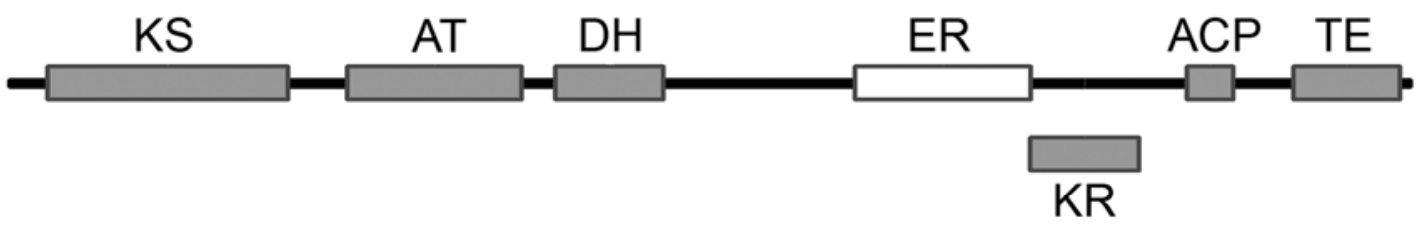

B
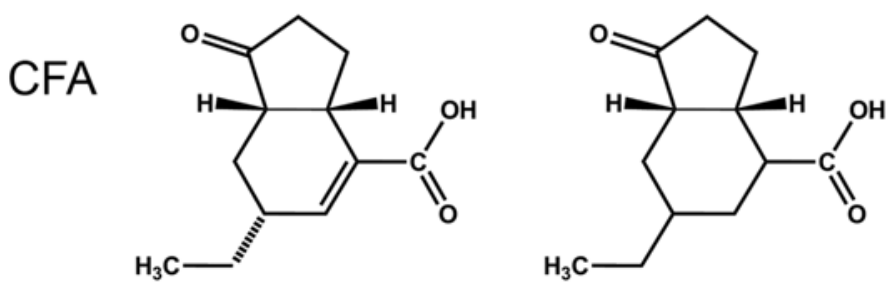

\section{S. scabies CFA-like compound}

Fig. 2. A, Organization of the predicted type-I polyketide synthase domains within the Pseudomonas syringae pv. tomato Cfa7 protein and the corresponding Cfa7 homologues from Pectobacterium atrosepticum and Streptomyces scabies. KS, ketosynthase; AT, acyltransferase; DH, dehydratase; KR, ketoreductase; ER, enoylreductase; ACP, acyl carrier protein; TE, thioesterase. The predicted ER domain that is unique to the $S$. scabies homologue is indicated in white. B, Structure of coronafacic acid (CFA) from Pseudomonas syringae and a predicted structure for the CFA-like compound produced by S. scabies 87-22. 
al. 1987; Leskiw et al. 1991). RT-PCR analysis demonstrated that expression of the $c f a$-like biosynthetic genes is also significantly reduced in a $S$. scabies $\triangle$ bldA mutant compared with the WT. PCR products for $c f a 5$, $c f a 6$, and $c f l$ were barely visible after 28 cycles (not shown) and were slightly more visible with 30 PCR cycles (Fig. 5B). On the other hand, transcription of neither scab79581 nor scab79591 was affected in the bldA mutant (Fig. 5B), supporting the notion that Scab79591 does not activate expression from its own promoter.

\section{The product of the $c f a$-like biosynthetic cluster} mimics COR in inducing hypertrophy of potato tissue.

The COR phytotoxin from $P$. syringae is known to induce a variety of symptoms in the plant host, including chlorosis, inhibition of root elongation, and stimulation of ethylene production (Bender et al. 1999b). In addition, COR has been reported to elicit the formation of hypertrophic outgrowths in potato tuber tissue (Sakai et al. 1979), an effect that has been utilized as a semiquantitative bioassay for detecting COR activity (Gnanamanickam et al. 1982; Bender et al. 1989; Volksch et al. 1989). To examine the biological activity of the $S$. scabies CFA-like molecule, we first constructed a KO strain of the $c f a-$ like biosynthetic cluster by replacing the $c f a 6$ type-I PKS gene
(Fig. 1A) with a [hyg+oriT] disruption cassette. Gene replacement was performed in both the WT (87-22) strain and in a thaxtomin A-deficient $(\Delta t x t A)$ strain (Table 3$)$ in order to assess the activity of the CFA-like molecule in both the presence and absence of thaxtomin A. Furthermore, we constructed CFA-like overexpression (OE) strains in both the WT and $\Delta t x t A$ backgrounds by overexpressing the scab79591 regulatory gene from the ermEp* promoter. Strains (WT, WT/vector control, WT/ CFA-like OE, $\Delta c f a 6 \_12-1, \Delta t x t A, \Delta t x t A$ /vector control, $\Delta t x t A /$ CFA-like OE, and $\left.\Delta t x t A / \Delta c f a 6 \_1\right)$ were then grown in OBB medium for 7 days and culture supernatants were filter sterilized and tested for hypertrophy activity. Although we did not observe any outgrowths of potato tuber tissue with any of the WT background culture filtrates (due to extensive necrosis of the potato tissue by thaxtomin A) (data not shown), we did see a small amount of outgrowth formation with the $\Delta t x t A$ and $\Delta t x t A /$ vector control culture filtrates (Fig. 6A and B). The extent of tissue hypertrophy was significantly increased when potato tissue was treated with the $\Delta t x t A / C F A$-like OE sample, whereas no hypertrophic outgrowths were observed with the $\Delta t x t A /$ $\Delta c f a 6 \_1$ culture filtrate or with uninoculated OBB medium (Fig. 6A and B). The degree of tissue hypertrophy induced by the $S$. scabies supernatants was significantly less than that ob-

Table 2. Streptomyces strains, geographical origin, pathogenicity, and DNA hybridization to probes specific for $c f a 6$ and $c f a 7$

\begin{tabular}{|c|c|c|c|c|}
\hline Strain $^{a}$ & Isolated from & Pathogenicity $^{\mathrm{b}}$ & $c f a 6^{\mathrm{c}, \mathrm{d}}$ & $c f a 7^{\mathrm{c}, \mathrm{e}}$ \\
\hline \multicolumn{5}{|l|}{ S. scabies strains } \\
\hline $87-22(\mathrm{WT})$ & Wisconsin, United States & + & + & + \\
\hline $83-08$ & Long Island NY, United States & + & + & + \\
\hline 84-34 (ATCC49173 $)$ & Upstate NY, United States & + & + & + \\
\hline $84-70$ & Maine, United States & + & + & + \\
\hline $84-232$ & West Virginia, United States & + & + & + \\
\hline $85-08$ & Maine, United States & + & + & + \\
\hline $85-30$ & Ohio, United States & + & + & + \\
\hline $87-27$ & Wisconsin, United States & + & + & + \\
\hline $87-67$ & Wisconsin, United States & + & + & + \\
\hline 89-04 & Alaska, United States & + & - & - \\
\hline $95-17$ & South Africa & + & + & + \\
\hline $95-18$ & South Africa & + & + & + \\
\hline $95-22$ & South Africa & + & + & + \\
\hline $96-01$ & New Brunswick, Canada & + & - & - \\
\hline $96-04$ & Nova Scotia, Canada & + & + & + \\
\hline $96-06$ & Ontario, Canada & + & + & + \\
\hline $96-08$ & Alberta, Canada & + & - & - \\
\hline $96-15$ & Germany & + & + & + \\
\hline $96-16$ & Germany & - & + & + \\
\hline \multicolumn{5}{|l|}{ S. turgidiscabies strains } \\
\hline 94-08 (CAR 8) & Japan & + & - & - \\
\hline $94-10(\mathrm{Hi}-\mathrm{C}-16)$ & Japan & + & - & - \\
\hline $94-16(\mathrm{~S}-2)$ & Japan & + & - & - \\
\hline 94-19 (SS-9) & Japan & + & - & - \\
\hline 94-21 (SS-13) & Japan & + & - & - \\
\hline 94-22 (KO-G-2) & Japan & + & - & - \\
\hline 94-23 (KO-G-6) & Japan & + & - & - \\
\hline 98-01 $\left(\mathrm{SY} 9113^{\mathrm{T}}\right)$ & Japan & + & - & - \\
\hline 98-05 (ТМH93-6) & Japan & + & - & - \\
\hline $98-15(91 \mathrm{Ki}-15)$ & Japan & + & - & - \\
\hline 98-25 (SMN-2) & Japan & + & - & - \\
\hline \multicolumn{5}{|l|}{ S. acidiscabies strains } \\
\hline $84-45$ & Maine, United States & + & - & - \\
\hline $84-104$ & Upstate New York, United States & + & - & - \\
\hline $84-110\left(\right.$ ATCC $\left.49003^{\mathrm{T}}\right)$ & Maine, United States & + & - & - \\
\hline $84-182$ & Maine, United States & + & - & - \\
\hline $85-06$ & West Virginia, United States & + & - & - \\
\hline $90-25$ & Maine, United States & + & - & - \\
\hline $98-48$ & Japan & - & - & - \\
\hline $98-49$ & Japan & + & - & - \\
\hline
\end{tabular}

a $\mathrm{T}=$ type strain and $\mathrm{WT}=$ wild type.

${ }^{\mathrm{b}}$ Pathogenicity (thaxtomin A production) was assessed using a radish seedling bioassay; $+=$ pathogenic and $-=$ nonpathogenic.

${ }^{c}$ Symbols + and $-=$ hybridization and no hybridization, respectively.

${ }^{\mathrm{d}}$ The $c f a 6$-specific probe was generated using the primers DRB209 and DRB210.

${ }^{\mathrm{e}}$ The $c f a 7$-specific probe was generated using the primers DRB363 and DRB364. 
served with pure COR (500 ng) (Fig. 6A), which may reflect differences in molecule concentrations used in this assay. Alternatively, this bioassay may not be as sensitive for detecting the activity of the CFA-like molecule due to the predicted structural differences compared with COR.

The $S$. scabies $c f a$ mutant shows an altered virulence phenotype compared with the WT.

The role of the $c f a$-like biosynthetic cluster in S. scabies virulence was assessed using an in vitro tobacco seedling bioassay. Three separate isolates of the $\Delta c f a 6$ mutant strain $\left(\Delta c f a 6 \_8-1\right.$, 12-1, and 14-1) were tested in this bioassay. All three isolates produced WT levels of thaxtomin A and secreted WT levels of the Nec1 virulence protein (data not shown). The WT and $\Delta c f a 6$ mutant strains all caused severe stunting of shoots and roots compared with the control plants, and chlorosis and eventual death was observed upon extended incubation (data not shown).
However, the WT strain also caused extensive necrosis and swelling of primary and lateral roots, which was most evident at the root tips (Fig. 6C and D). The $\Delta c f a 6$ mutant strains, on the other hand, caused considerably less root necrosis and swelling in comparison (Fig. 6C and D). Overexpression of the $c f a$-like biosynthetic cluster in strain 87-22 did not significantly affect the WT phenotype in this bioassay (data not shown).

\section{DISCUSSION}

Through expression analyses and mutational studies, we have demonstrated that a novel secondary metabolite biosynthetic cluster identified in the $S$. scabies 87-22 genome sequence contributes to host-pathogen interactions. Bioinformatics analyses of this cluster predicted that it synthesizes a metabolite that is structurally related to the virulence-associated CFA compound from $P$. syringae as well as the putative CFA molecule

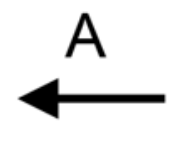

(2)

(5)

(7)

(10)

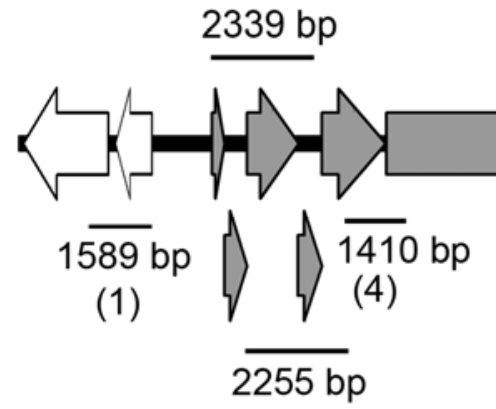

(3)
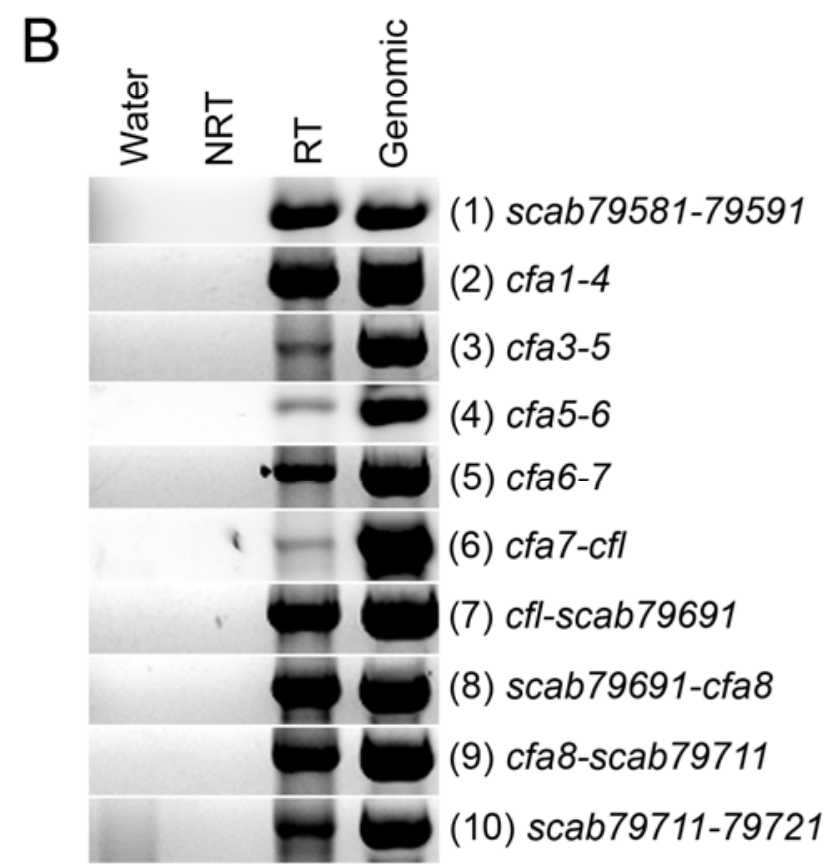

(6)

$2485 \mathrm{bp}$

(8)

Fig. 3. Demonstration of co-transcription of the Streptomyces scabies cfa-like genes using reverse-transcriptase polymerase chain reaction (RT-PCR). A, Schematic diagram showing the location and size of the PCR products (1 to 10) that were amplified using $S$. scabies cDNA as the template. The black arrows represent the two messenger RNA transcripts that were identified in this study. B, Agarose gel electrophoresis of PCR products generated using $S$. scabies cDNA as template (RT lane). The cDNA was generated from DNAse-treated RNA that was harvested from 48-h thaxtomin-defined medium with cellobiose (TDM-C) cultures. Negative control reactions included replacing the cDNA template with water (Water lane) or with RT reaction mix in which the RT enzyme was omitted (NRT lane). S. scabies 87-22 genomic DNA served as the template for positive control reactions (Genomic lane). 


\section{Fluorescence}

\section{Transmission}

87-22/plJ8641

87-22/pRLDB43-16
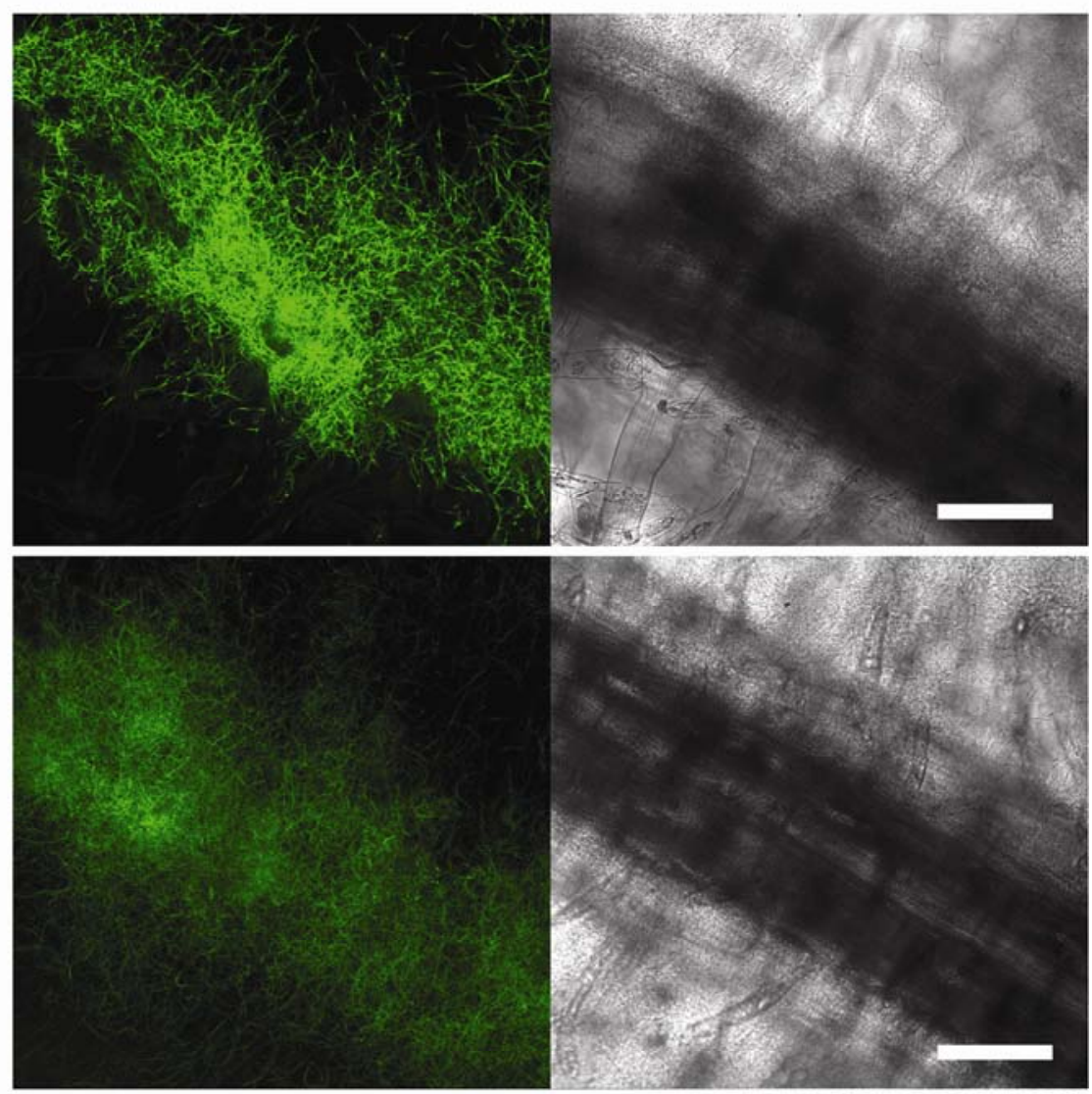

87-22/pRLDB42-2

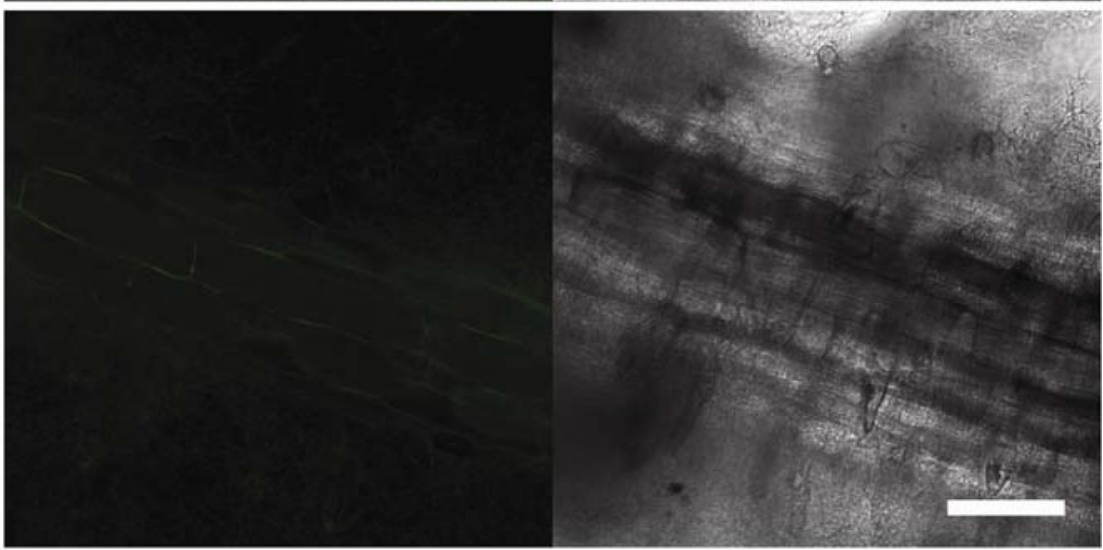

Control

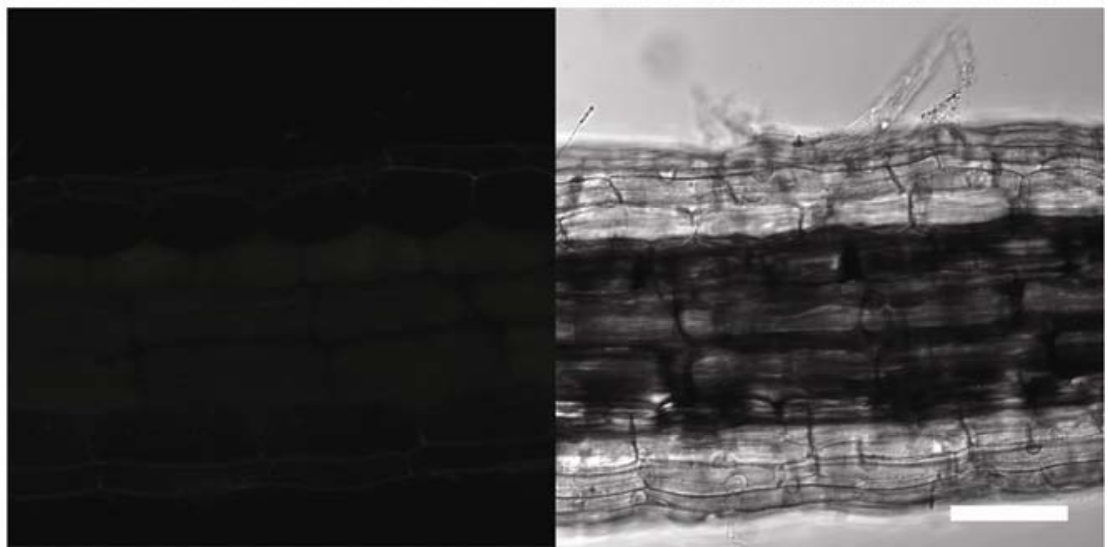

Fig. 4. In planta expression analysis of the Streptomyces scabies cfa cluster using confocal fluorescence microscopy. Tobacco seedlings were infected with the $S$. scabies green fluorescent protein reporter strains 87-22/pIJ8641 (positive control), 87-22/pRLDB43-16 (cfal promoter reporter), and 8722/pRLDB42-2 (negative control), and colonized tobacco roots were analyzed for fluorescence 4 days post inoculation. Uninoculated plants (Control) were included in the analysis. The fluorescence and transmission micrographs shown were captured in a single focal plane. Scale bars $=75 \mu \mathrm{m}$. 


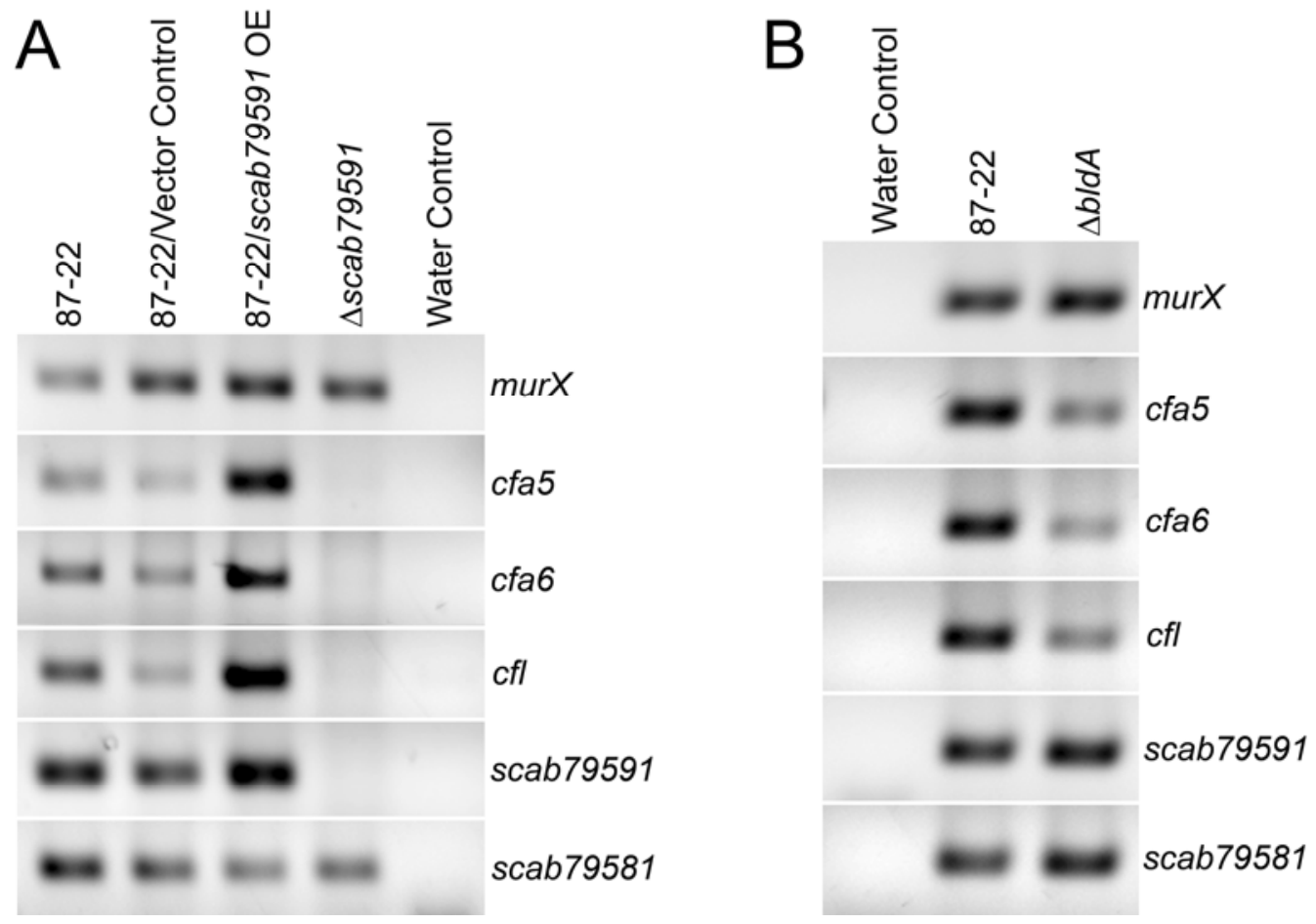

Fig. 5. Reverse-transcriptase polymerase chain reaction (PCR) analysis showing the dependence of Streptomyces scabies cfa-like gene expression on A, Scab79591 and B, bldA. S. scabies strains were grown for $72 \mathrm{~h}$ in thaxtomin-defined medium with cellobiose (TDM-C) and RNA was prepared and reverse transcribed to cDNA. PCR reactions were performed using either cDNA or water as the template; products were generated using $\mathbf{A}, 28$ cycles or $\mathbf{B}, 30$ cycles of PCR. The murX gene served as a loading control.

Table 3. Bacterial strains, plasmids, and cosmids used in this study

\begin{tabular}{|c|c|c|}
\hline Strain, plasmid or cosmid & Description $^{\mathrm{a}}$ & Reference or source \\
\hline \multicolumn{3}{|l|}{ Escherichia coli strains } \\
\hline DH5 $\alpha$ & General cloning host & Gibco-BRL \\
\hline One Shot Top10 & Cloning host for TOPO TA Cloning kit & Invitrogen \\
\hline ET12567 & $d a m^{-}, d \mathrm{~cm}^{-}, h s d S^{-} ;$nonmethylating host $(\mathrm{CmR})$ & MacNeil et al. 1992 \\
\hline BW25113 & Host for Redirect PCR targeting system & Gust et al. 2003 \\
\hline \multicolumn{3}{|c|}{ Streptomyces scabies strains } \\
\hline $87-22$ & S. scabies wild-type strain & Loria et al. 1995 \\
\hline$\Delta b l d A$ & Global regulatory mutant; 87-22 derivative with a deletion of the bldA tRNA gene (AprR) & This study \\
\hline$\triangle t x t A$ & Thaxtomin deficient mutant; $87-22$ derivative with a deletion of the $t x t A$ gene (AprR) & Johnson et al. 2009 \\
\hline$\Delta s c a b 79591$ & CFA-like regulatory mutant; 87-22 derivative with a deletion of the $s c a b 79591$ gene (HygR) & This study \\
\hline$\Delta c f a 6$ & CFA-like biosynthetic mutant; 87-22 derivative containing a deletion of the $c f a 6$ gene (HygR) & This study \\
\hline$\Delta t x t A / \Delta c f a 6$ & $\begin{array}{l}\text { Thaxtomin/CFA-like double mutant; } \Delta t x t A \text { derivative with a deletion of the } c f a 6 \text { gene } \\
\text { (AprR, HygR) }\end{array}$ & This study \\
\hline \multicolumn{3}{|c|}{ 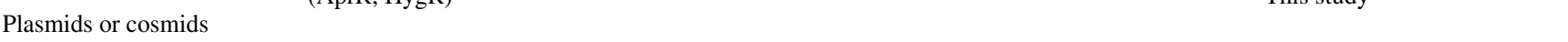 } \\
\hline pUZ8002 & $\begin{array}{l}\text { Supplies transfer functions for mobilization of oriT-containing vectors from E. coli to } \\
\text { Streptomyces }(\mathrm{KnR})\end{array}$ & Kieser et al. 2000 \\
\hline pCR2.1TOPO & Phagemid cloning vector for PCR products (AmpR, KnR) & Invitrogen \\
\hline pIJ8641 & ermEp*-egfp reporter plasmid; integrates into the Streptomyces $\phi C 31$ attB site (AprR) & J. Sun, unpublished data \\
\hline pRLDB42-2 & pIJ8641 derivative; promoterless egfp reporter plasmid (AprR) & This study \\
\hline pRLDB43-16 & pRLDB42-2 derivative; $S$. scabies cfalp-egfp reporter plasmid (AprR) & This study \\
\hline pLST9828 & $\begin{array}{l}\text { pSET152 derivative containing the ermEp* promoter; integrates into the Streptomyces } \phi \mathrm{C} 31 \\
\text { attB site (AprR) }\end{array}$ & Butler et al. 1999 \\
\hline pAU3-45 & pSET152 derivative containing the $t s r$ coding sequence + promoter (AprR, ThioR) & Bignell et al. 2005 \\
\hline pRLDB50-1a & pLST9828 derivative containing the $t s r$ coding sequence + promoter (AprR, ThioR) & This study \\
\hline pRLDB51-1 & pRLDB50-1a derivative; scab79591 overexpression plasmid (AprR, ThioR) & This study \\
\hline SuperCos1 & Cosmid cloning vector (AmpR, KnR) & Stratagene \\
\hline Cosmid 158 & SuperCos 1 derivative containing the $S$. scabies $87-22$ cfa-like locus (AmpR, KnR) & This study \\
\hline Cosmid 1770 & SuperCos1 derivative containing the S. scabies $87-22$ cfa-like locus (AmpR, KnR) & This study \\
\hline Cosmid 2237 & SuperCos1 derivative containing the $S$. scabies $87-22$ bldA gene (AmpR, KnR) & This study \\
\hline pIJ773 & $\begin{array}{l}\text { Template for REDIRECT PCR targeting system, contains the }[\text { aac }(3) I V+o r i T] \text { disruption } \\
\text { cassette (AmpR, AprR) }\end{array}$ & Gust et al. 2003 \\
\hline pIJ10700 & $\begin{array}{l}\text { Template for REDIRECT PCR targeting system, contains the }[\text { hyg+oriT] disruption cassette } \\
\text { (AmpR, HygR) }\end{array}$ & S. O'Rouke, unpublished data \\
\hline pACRL2-5 & scab79591 deletion construct derived from Cosmid 158 (AmpR, KnR, HygR) & This study \\
\hline pRLDB23-1 & bldA deletion construct derived from Cosmid 2237 (AmpR, KnR, AprR) & This study \\
\hline pRLDB24-1 & cfa6 deletion construct derived from Cosmid 1770 (AmpR, KnR, HygR) & This study \\
\hline
\end{tabular}

${ }^{a} \mathrm{CmR}, \mathrm{HygR}, \mathrm{KnR}, \mathrm{AmpR}, \mathrm{AprR}$, and ThioR = chloramphenicol, hygromycin, kanamycin, ampicillin, apramycin, and thiostrepton resistance, respectively. 

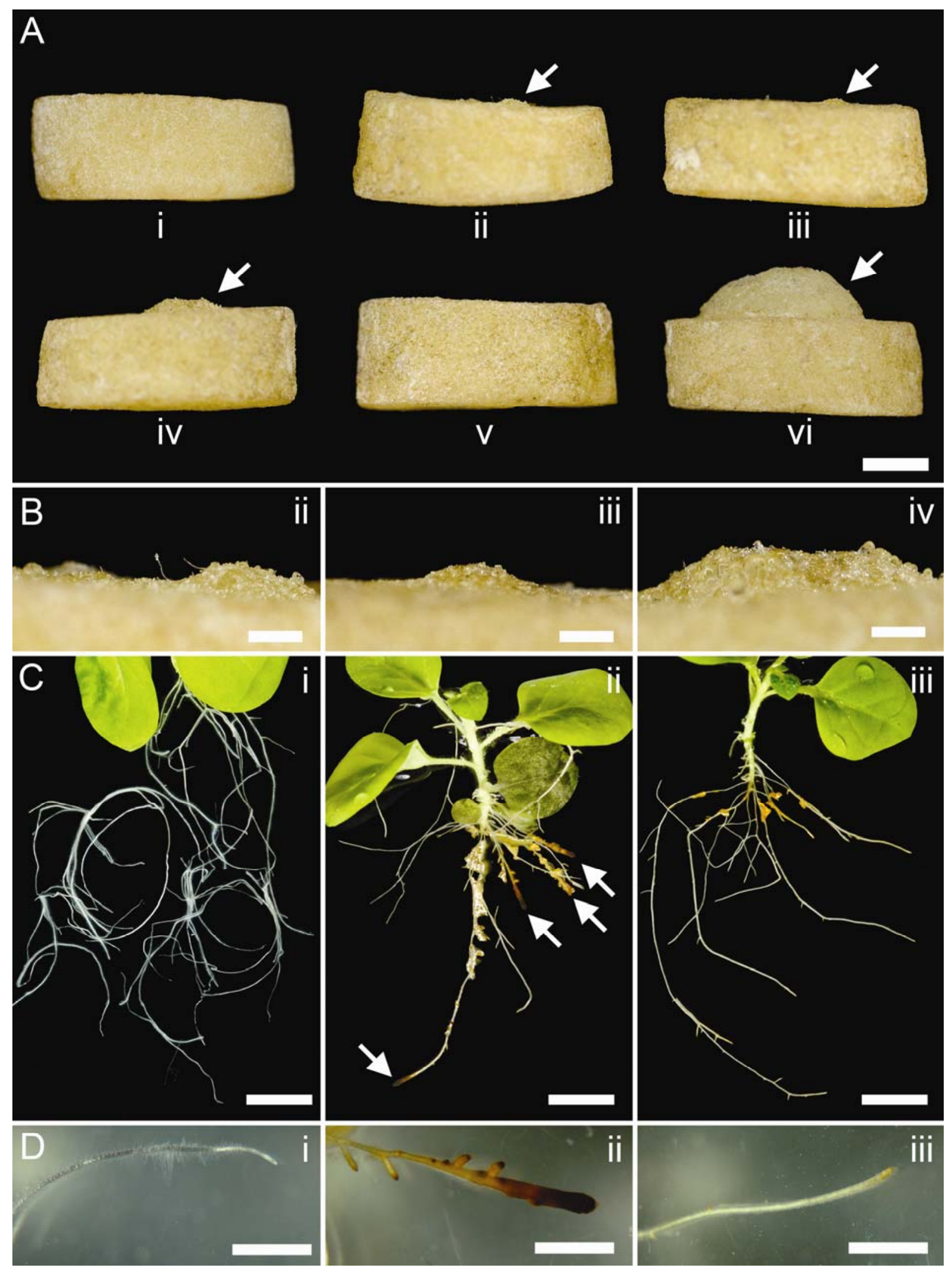

Fig. 6. A, Potato tuber disk assay for detection of hypertrophy. Tuber disks were treated with $25 \mu$ of filter-sterilized supernatant from cultures of Streptomy-

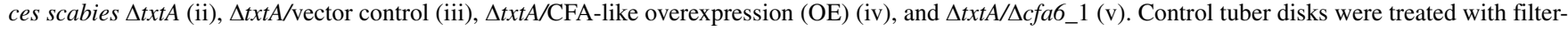
sterilized oat bran broth medium (i) or with pure coronatine $(500 \mathrm{ng})$ (vi). Arrows indicate areas of hypertrophy caused by the specified treatments. Scale bar $=5$ $\mathrm{mm}$. B, Close-up images of potato tuber disks showing the hypertrophy caused by the $\Delta t x t A$ (ii), $\Delta t x t A /$ vector control (iii), and $\Delta t x t A / C F A-l i k e ~ O E$ (iv) culture filtrates. Scale bar $=1 \mathrm{~mm}$. C, Tobacco root disease symptoms induced by Streptomyces scabies infection. Tobacco seedlings (Nicotiana tabacum cv. Xanthi) growing on Murashige and Skoog agar medium salts + 2\% sucrose medium were infected with wild-type S. scabies 87-22 (ii) or $\Delta$ cfa6_12-1 (iii) or were mock-infected (i) and were then incubated at $21 \pm 2{ }^{\circ} \mathrm{C}$ and $12 \mathrm{~h}$ of daylight for 6 weeks. Arrows indicate roots which have undergone extensive swelling and necrosis as a result of infection. Scale bar $=10 \mathrm{~mm}$. D, Close-up image of a tobacco root from an uninfected plant (i), a 87-22-infected plant (ii), and a $\Delta c f a 6 \_12-1$-infected plant (iii). Scale bar $=3 \mathrm{~mm}$. 
from Pectobacterium atrosepticum. Our work here is the first report of a $c f a$-like biosynthetic cluster present in a grampositive plant pathogen, and the conservation of $c f a$ and $c f a$ like biosynthetic clusters in different plant-pathogenic bacteria suggests that CFA and CFA-related compounds may be even more important for host-pathogen interactions than previously realized.

Although the metabolite produced by the $S$. scabies biosynthetic cluster is likely similar to CFA, the in silico analyses of the biosynthetic genes strongly suggest that this metabolite is also novel in structure. For example, the C-C double bond that is present in CFA is likely absent from the $S$. scabies metabolite due to the presence of an ER domain in the Cfa7 PKS that is absent from the corresponding $P$. syringae Cfa7 protein (Fig. 2). Furthermore, the $S$. scabies cluster contains additional genes that could function as tailoring enzymes for the polyketide backbone. It is interesting to note, however, that a homologue of the $P$. syringae $\mathrm{Cfl}$ protein is conserved in the $S$. scabies cluster. $\mathrm{Cfl}$ is believed to be responsible for ligating CFA to the ethylcyclopropyl amino acid, CMA, to form the COR phytotoxin, and it is also thought to generate other coronafacoyl-amino acid conjugates such as CFA-Ile, CFA-Val, CFA-Ser, and CFA-Thr, and may additionally function in CFA biosynthesis (Bender et al. 1999b). The presence of a Cfl homologue in S. scabies suggests that the CFA-like molecule might also be linked to an amino acid component to form compounds similar to coronafacoylamino acid conjugates. Because $S$. scabies does not contain the biosynthetic genes for CMA, however, it is unlikely that this organism produces COR, as similarly reported for Pectobacterium atrosepticum (Bell et al. 2004).

The $S$. scabies $c f a$-like cluster is expressed during plant-microbe interactions as well as in liquid culture under conditions that induce thaxtomin A production. Furthermore, at least two mRNA transcripts are produced during gene expression, one of which is approximately $27 \mathrm{~kb}$ in size and includes most of the coding sequences from the gene cluster. A similar result has been reported for the $P$. syringae cfa gene cluster, where all of the biosynthetic genes are expressed as a single large transcript (Liyanage et al. 1995). The smaller, approximately 3-kb transcript identified in $S$. scabies includes a transcriptional regulatory gene, scab79591, which functions as a positive activator of the $c f a$-like biosynthetic genes but does not control its own expression. A second gene, scab79581, is co-transcribed with scab79591 and may also play a role in gene regulation, although it is currently unclear what the role of the protein product would be. The Scab79591 regulatory protein belongs to a novel family of Streptomyces transcriptional regulators whose members are all associated with secondary metabolite biosynthetic clusters and contain an N-terminal PAS fold-like domain and a C-terminal LuxR-type DNA-binding domain. Two other members of this family, NysRIV and PimM, which are associated with the antibiotic biosynthetic clusters for nystatin and pimaricin, respectively, have also been demonstrated to function as pathway-specific transcriptional activators, and PimM also does not affect the expression of its own gene (Anton et al. 2007; Sekurova et al. 2004). Expression of the S. scabies $c f a$-like biosynthetic genes is also dependent on the bldA tRNA, which is responsible for translation of the rare UUA codon in Streptomyces spp. mRNA. There is evidence that the availability of the bldA tRNA is growth-phase dependent in streptomycetes and that $b l d A$ is important for post-transcriptional regulation of TTA-containing genes (Chater and Chandra 2008). A TTA codon is present in the scab79591 regulatory sequence and a second TTA codon is also found in the cfa3 biosynthetic gene; this indicates that production of the CFAlike metabolite is likely dependent on the availability of bldA in S. scabies.
Although the $S$. scabies CFA-like biosynthetic mutant displayed a reduced virulence phenotype with regard to root disease symptoms (Fig. 6C and D), the strain still caused extensive stunting of roots and shoots as well as chlorosis and eventual death of the tobacco plant host. Furthermore, the genes responsible for synthesis of the polyketide backbone were only found in group $1 \mathrm{~S}$. scabies strains and were absent from group 2 strains as well as various strains of $S$. turgidiscabies and $S$. acidiscabies. This suggests that the $c f a$-like biosynthetic cluster is not essential for plant pathogenicity in these organisms. Instead, it appears to contribute to the severity of disease symptoms induced by group $1 S$. scabies. Although COR is a major virulence factor in $P$. syringae, it also contributes mainly to disease severity and is not required for pathogenicity (Bender et al. 1999b). Similarly, cfa mutants of Pectobacterium atrosepticum are significantly reduced but not abolished in pathogenicity (Bell et al. 2004). Recently, a cytokinin biosynthetic cluster identified in S. turgidiscabies Car8 was shown to contribute to plant-microbe interactions; however, this cluster is not conserved in either S. scabies or S. acidiscabies (Joshi and Loria 2007; Kers et al. 2005). It is conceivable that pathogenic Streptomyces spp. might utilize lineage-specific virulence determinants to help establish an infection of the plant host in addition to those virulence determinants (thaxtomin $\mathrm{A}, \mathrm{Nec} 1$, and TomA) that are shared by all or most pathogenic streptomycetes (Kers et al. 2005).

The precise role of the CFA-like metabolite in S. scabies plant pathogenicity is unclear at this time. The COR phytotoxin of $P$. syringae contributes to increased bacterial populations in planta as well as lesion expansion in several plant hosts, including ryegrass, soybean, tomato, and several crucifers (Bender et al. 1999a). In addition, it was recently demonstrated that COR facilitates entry of the pathogen into host leaves by suppressing the closure of stomata, a response that forms part of the plant basal defense system (Melotto et al. 2006, 2008b). COR is structurally related to the plant hormone jasmonic acid (JA) as well as bioactive JA derivatives such as jasmonoyl-isoleucine (JA-Ile) (Katsir et al. 2008a). JA-Ile and structurally related JA-conjugates (e.g., JA-Val) are important signaling molecules in plant defense responses to herbivores and necrotropic pathogens (Katsir et al. 2008a). They promote the interaction of the COI1 F-box protein, which determines the substrate specificity of the SCF-type E3 ubiquitin ligase, $\mathrm{SCF}^{\mathrm{COI} 1}$, with a certain class of jasmonate ZIM-domain (JAZ) repressor proteins; this, in turn, leads to the ubiquitination and subsequent degradation of the JAZ proteins and the induction of JA-responsive genes (Katsir et al. 2008b; Melotto et al. 2008a; Thines et al. 2007). Recently, it was demonstrated that COR functions as a molecular mimic of JA-Ile by promoting COI1-JAZ interactions and inducing JA-dependent gene expression (Katsir et al. 2008b; Melotto et al. 2008a). Activation of JA signaling by COR, in turn, suppresses salicylic acid (SA) signaling, which is important in plant defense against biotropic pathogens such as $P$. syringae (Glazebrook 2005). Thus, COR functions to manipulate plant hormone signaling in order to enhance the susceptibility of the host to pathogen infection. Because the S. scabies CFA-like compound appears to share some biological activity with COR, as deduced by the potato hypertrophy bioassay, it is possible that this compound also functions to suppress plant defense responses during Streptomyces spp. infection. Interestingly, studies in our lab suggest that JA-dependent signaling is more important than SA-dependent signaling for host defense against pathogenic streptomycetes (M. Joshi and R. Loria, unpublished data). It is intriguing to speculate that the CFA-like metabolite might enhance pathogen infection by functioning as an antagonist of 
JA-dependent signaling rather than as a stimulant like COR. Such an activity might be the result of structural differences between COR and the $S$. scabies molecule. Therefore, purification of the CFA-like metabolite for both structural elucidation and assessment of biological activity is the next logical step in characterizing this molecule and its role in S. scabies pathogenicity.

\section{MATERIALS AND METHODS}

\section{Bacterial strains, culture conditions, and genetic manipulations.}

S. scabies, $S$. acidiscabies, and $S$. turgidiscabies strains used in this study are listed in Tables 2 and 3. S. scabies 87-22 (WT strain) and other strains were routinely cultivated on the International Streptomyces Project (ISP) medium 2 and medium 4 (BD Biosciences, San Jose, CA, U.S.A.) at $28^{\circ}$ C. Where required, the medium was supplemented with apramycin $(100$ $\mu \mathrm{g} / \mathrm{ml})$, hygromycin B $(100 \mu \mathrm{g} / \mathrm{ml})$, kanamycin $(50 \mu \mathrm{g} / \mathrm{ml})$, thiostrepton $(25 \mu \mathrm{g} / \mathrm{ml})$, or nalidixic acid $(50 \mu \mathrm{g} / \mathrm{ml})$. Spore suspensions of Streptomyces strains were prepared from 7- to 10-day-old ISP-4 plates and were quantified by dilution plating onto nutrient agar medium (Kieser et al. 2000). DNA was extracted from Streptomyces cultures grown in TSB medium (BD Biosciences) for 24 to $48 \mathrm{~h}$ at $28^{\circ} \mathrm{C}$ using the MasterPure gram-positive DNA purification kit (Epicentre Biotechnologies, Madison, WI, U.S.A.) according to the manufacturer's instruction. Streptomyces spores $\left(10^{6}\right.$ to $\left.10^{8}\right)$ were pregerminated in $2 \times$ YT as described (Kieser et al. 2000) and then grown in TSB, TDM-C, or OBB (Johnson et al. 2007) for RNA extraction and analysis. Escherichia coli strains used in this study are listed in Table 3 . Strains were grown and maintained as described previously (Sambrook et al. 1989) and plasmid-containing cultures were supplemented with ampicillin $(100 \mu \mathrm{g} / \mathrm{ml})$, kanamycin $(50 \mu \mathrm{g} / \mathrm{ml})$, chloramphenicol $(25 \mu \mathrm{g} /$ $\mathrm{ml})$, hygromycin $\mathrm{B}(100 \mu \mathrm{g} / \mathrm{ml})$, or apramycin $(100 \mu \mathrm{g} / \mathrm{ml})$. DNA was manipulated in E. coli DH5 $\alpha$ using standard procedures (Sambrook et al. 1989) and all cosmids, plasmid vectors, and recombinant plasmids used are listed in Table 3. Sequencing of plasmid and PCR products was performed by the Cornell University Life Sciences Core Laboratories Center. All oligonucleotide primers used for sequencing or PCR are listed in Supplementary Table S1. Intergeneric conjugal transfer of DNA into Streptomyces spp. was performed according to the protocol described previously (Kieser et al. 2000) except that the spores were not heat shocked. DNA was transferred from the methylation-deficient $E$. coli ET12567 strain that carried the helper plasmid pUZ8002.

\section{Southern analysis of Streptomyces spp. DNA.}

Genomic DNA ( $5 \mu \mathrm{g}$ ) was digested overnight with an appropriate restriction enzyme, then separated by electrophoresis on a $1 \%$ agarose gel and transferred overnight to nylon membrane (Whatman Co., Sanford, ME, U.S.A.) under neutral conditions as described (Hopwood et al. 1985). Southern analysis was performed using digoxigenin (DIG)-labeled DNA probes (500 to $600 \mathrm{bp}$ ) that were generated by PCR using DIG-dUTP (Roche Diagnostics, Indianapolis, IN, U.S.A.) according to the manufacturer's protocol. Hybridizations were routinely carried out overnight at 50 to $55^{\circ} \mathrm{C}$ in DIG Easy Hyb solution (Roche), and membranes were washed twice for $15 \mathrm{~min}$ each time in solution I $(2 \times \mathrm{SSC}[1 \times \mathrm{SSC}$ is $0.15 \mathrm{M} \mathrm{NaCl}$ plus $0.015 \mathrm{M}$ sodium citrate] and $0.1 \%$ sodium dodecyl sulfate [SDS]) at 50 to $55^{\circ} \mathrm{C}$ and then twice for $15 \mathrm{~min}$ each time in solution II $(0.2 \times \mathrm{SSC}$ and $0.1 \% \mathrm{SDS})$ at $65^{\circ} \mathrm{C}$. Immunological detection of the hybridized probe was performed according to the manufacturer's direction (Roche Diagnostics).
RNA isolation and analysis of gene expression.

Streptomyces strains were grown in duplicate in $25 \mathrm{ml}$ of TDM-C, OBB, or TSB at $25 \pm 2{ }^{\circ} \mathrm{C}$ and $150 \mathrm{rpm}$ for 24 to 72 h. RNA was prepared from each culture as described previously (Joshi et al. 2007b), except that Turbo DNA-free DNAse (Ambion, Austin, TX, U.S.A.) was used to remove any contaminating genomic DNA in the samples. RT-PCR analysis of Streptomyces gene expression was carried out as described (Joshi et al. 2007b) using $2 \mu$ g of DNAse-treated RNA. NRT control templates (RT reactions without reverse-transcriptase enzyme addition) were included in the analysis to verify the absence of genomic DNA in the RNA samples. Taq DNA polymerase (New England Biolabs, Ipswich, MA, U.S.A.) was used for PCR amplification of cDNA templates, and dimethyl sulfoxide (DMSO) (5\%) was included in each reaction mix. murX (Joshi et al. 2007b) served as the control gene in these studies.

Analysis of co-transcription of the $S$. scabies $\boldsymbol{c f a}$-like genes.

RNA $(2 \mu \mathrm{g})$ isolated from 48-h TDM-C cultures was reverse-transcribed as described (Joshi et al. 2007b), and control reactions (NRT) were also performed as described above. PCR was performed using Phusion high-fidelity DNA polymerase (Finnzymes, Inc., Woburn, MA, U.S.A.) according to the manufacturer's protocol. DMSO $(5 \%)$ was included in all reactions, and control PCR templates included water, NRT reaction mix, and genomic DNA (20 ng). PCR products obtained from cDNA template were cloned into pCR2.1TOPO (Table 3 ) and were sequenced to verify their identity.

\section{In planta expression analysis}

of the $S$. scabies cfa-like cluster.

This was accomplished using a GFP promoter reporter system. The integrative plasmid pIJ8641, harboring the egfp gene expressed from ermEp* (Bibb et al. 1994), was first digested with $K p n I$ to release the ermEp* fragment. The resulting plasmid ends were religated together to form pRLDB42-2, which contained a promoterless egfp gene. Next, the scab79591-cfal intergenic region (1,492 bp) was PCR amplified using Cosmid 1770 as the template and the primers DRB282 and DRB283, and the resulting PCR product was cloned into pCR2.1TOPO and sequenced. The insert was then released from the TOPO vector by digestion with $E c o$ RI, the ends were blunted, and the fragment was ligated into EcoRV-digested pRLDB42-2. The resulting $c f a l$ promoter reporter plasmid (pRLDB43-16) was sequenced to confirm that the insert was present in the correct orientation, and was introduced into $S$. scabies $87-22$ by intergeneric conjugation from $E$. coli. In addition, pRLDB42-2 and pIJ8641 were separately conjugated into 87-22 to generate strains that were used as negative and positive controls, respectively, for fluorescence analysis.

Expression of the $c f a l$ promoter during plant-microbe interactions was determined using confocal laser scanning microscopy. Tobacco seeds (Nicotiana tabacum cv. Xanthi) were surface sterilized in $15 \%$ bleach (Clorox) and then incubated for 3 to 5 days at $4^{\circ} \mathrm{C}$ in the dark in sterile $0.1 \%$ phytagar (Gibco BRL Life Technologies, Grand Island, NY, U.S.A.). Seeds were aseptically transferred to Murashige and Skoog agar medium (MS) containing 2\% sucrose (Murashige and Skoog 1962) and were incubated at $21 \pm 2^{\circ} \mathrm{C}$ under a 12-h photoperiod for 7 to 8 days. The tobacco seedlings were then transferred to individual wells (two seedlings per well) in six-well plates containing $5 \mathrm{ml}$ of $0.5 \times \mathrm{MS}$ salts medium $(\mathrm{pH}$ 6) lacking organic additives. The medium in each well was inoculated with $10^{6}$ spores (in $50 \mu \mathrm{l}$ of water) of $S$. scabies GFP reporter strain or was mock inoculated with water. In addition, spores were inoculated into $5 \mathrm{ml}$ of $0.5 \times \mathrm{MS}$ medium lacking tobacco 
plant material. A total of six replicates (12 plants) were set up per treatment. The six-well plates were incubated with slow shaking (75 rpm) at $21 \pm 2{ }^{\circ} \mathrm{C}$ under a 12 -h photoperiod for 7 days, and GFP fluorescence from reporter strains colonizing tobacco seedling roots or in the control wells was analyzed using a Leica TCS SP2 microscope (Leica Microsystems, Wetzlar, Germany) as described (Joshi et al. 2007a). The assay was repeated twice.

\section{Targeted deletion of $S$. scabies 87-22 genes.}

Deletion of scab79591, cfa6, and bldA was accomplished using the Redirect PCR targeting system as described previously (Gust et al. 2003). Cosmids 158 (harboring the scab79591 gene), 1770 (containing the $c f a 6$ gene), and 2237 (containing the bldA gene) were each introduced in E. coli BW25113 carrying the arabinose-inducible $\lambda$ RED expression plasmid, pIJ790. Deletion cassettes ([hyg+oriT] for scab79591 and cfa6; [aac(3)IV+oriT] for bldA) were PCR amplified using pIJ10700 or pIJ773 (Table 3) as the template and using the primers DRB292 and DRB293 for scab79591, DRB180 and DRB181 for $c f a 6$, and DRB211 and DRB212 for bldA. The deletion cassettes were gel purified and then electroporated into $E$. coli cells (containing the appropriate cosmid) that had been induced with arabinose, and mutant cosmids that were isolated were verified by PCR or restriction digestion. The scab79591 mutant cosmid (pACRL2-5), the cfa6 mutant cosmid (pRLDB24-1), and the bldA mutant cosmid (pRLDB23-1) were then separately conjugated into $S$. scabies $87-22$ from $E$. coli, and resulting exconjugants were selected for resistance to hygromycin $B$ (pRLDB24-1 and pACRL2-5) or apramycin (pRLDB23-1) and sensitivity to kanamycin. Verification of the scab79591, cfa6, and bldA deletion strains was by Southern analysis and PCR (data not shown).

\section{Overexpression of scab79591.}

To overexpress the scab79591 gene, we first made a derivative of the Streptomyces integrative expression vector, pLST9828, so that it could be used in apramycin-resistant strains. The thiostrepton resistant gene $(t s r)$ and promoter region from pAU3-45 (Table 3) was PCR amplified using the primers DRB332 and DRB333, and the resulting product was cloned into pCR2.1TOPO and authenticated by sequencing. Next, the primers DRB460 and DRB461 were used to amplify the TOPO-cloned fragment to give an approximately 1,100-bp product flanked with NheI sites. The product was digested with NheI, gel purified, and then ligated into NheIdigested pLST9828 to give pRLDB50-1a. The scab79591 coding sequence was amplified by PCR using Cosmid 158 as the template and the primers DRB296 and DB297. The resulting product was cloned into pCR2.1TOPO, sequenced, then released by digestion of the TOPO clone with BamHI to give a 1,063-bp fragment. After gel purification, the scab79591-containing DNA fragment was ligated into BamHI-digested pRLDB50-1a to give pRLDB51-1, which was sequenced to confirm the correct orientation of the insert. Both pRLDB50-1a and pRLDB51-1 were then introduced into WT S. scabies $87-22$ as well as a thaxtomin-deficient mutant, $\triangle t x t A$ (Table 3), via intergeneric conjugation from $E$. coli.

\section{Biological activity of the $S$. scabies CFA-like compound.}

The $S$. scabies CFA-like compound was tested for the ability to cause hypertrophy of potato tuber disks. Strains of $S$. scabies were grown for 7 days in the dark at $25 \pm 2{ }^{\circ} \mathrm{C}$ in 5 to 50 $\mathrm{ml}$ of $\mathrm{OBB}$ medium, after which the mycelia were pelleted and the supernatants were filter-sterilized using $0.2-\mu \mathrm{m}$ cellulose acetate filters (VWR). Potato tuber disks (cv. Chippewa) were prepared as described previously (Loria et al. 1995) and were placed onto moist sterile filter paper in petri dishes. Sterile paper disks $(0.6 \mathrm{~cm}$ in diameter) were then placed on top of each tuber disk, and culture filtrates $(25 \mu \mathrm{l})$ were pipetted onto each paper disk. Five tuber disks were used per treatment, and filtersterilized OBB $(25 \mu \mathrm{l})$ served as the negative control while pure coronatine (500 $\mathrm{ng}$ in water) functioned as a positive control. The petri dishes were then wrapped with parafilm and were incubated at $21 \pm 2{ }^{\circ} \mathrm{C}$ in the dark for 10 days. The assay was repeated once using different biological replicates of the culture filtrates.

\section{Virulence bioassays.}

An in vitro radish seedling bioassay was used to assess thaxtomin A production and virulence by strains of $S$. scabies, $S$. turgidiscabies, and $S$. acidiscabies. Seeds (cv. Burpee White) were surface sterilized in $15 \%$ (vol/vol) bleach (Clorox) and then incubated for $30 \mathrm{~h}$ at $21 \pm 2{ }^{\circ} \mathrm{C}$ in the dark in a petri dish containing moistened filter paper. Germinated seeds were placed into wells (13 $\mathrm{mm}$ in diameter) that were made in $1.5 \%$ agar-water plates. Streptomyces strains were grown in TSB for $48 \mathrm{~h}$ at $28^{\circ} \mathrm{C}$, and then the mycelia were pelleted, washed twice with sterile water, and resuspended in $2 \mathrm{ml}$ of water. Mycelial suspensions $(200 \mu \mathrm{l})$ were each pipetted into six agar wells containing the radish seed, while control seed were treated with $200 \mu \mathrm{l}$ of sterile water. The plates were wrapped with parafilm and incubated at $21 \pm 2^{\circ} \mathrm{C}$ under a 12-h photoperiod for 7 days.

An in vitro tobacco bioassay was performed to assess the virulence phenotype of the $\Delta c f a 6$ mutant. $N$. tabacum cv. Xanthi seeds were surface sterilized as described above and then incubated in $0.1 \%$ phytagar for 5 days in the dark at $4^{\circ} \mathrm{C}$. The seeds were aseptically transferred to MS agar medium $(\mathrm{pH}$ 5.8) containing $2 \%$ sucrose in Magenta boxes and were incubated at $21 \pm 2{ }^{\circ} \mathrm{C}$ under a 12-h photoperiod for 15 to 20 days. Spores of S. scabies $\left(10^{8}\right.$ to $\left.10^{9}\right)$ in sterile water $(1 \mathrm{ml})$ were used to inoculate each Magenta box in the vicinity of the plant roots while control plants were treated with $1 \mathrm{ml}$ of sterile water. In total, 30 to 40 plants were used per treatment, and disease symptoms were assessed 6 to 8 weeks post inoculation. The assay was repeated twice.

\section{Analysis of thaxtomin A production and secretion of Nec1.}

For thaxtomin A production, Streptomyces strains were grown in $6 \times 5 \mathrm{ml}$ of OBB in six-well plates for 7 days at $25 \pm$ $2{ }^{\circ} \mathrm{C}$ with moderate shaking (approximately $120 \mathrm{rpm}$ ). Mycelia were pelleted by centrifugation and were discarded. Thaxtomin A was purified from culture supernatants and was analyzed by high-performance liquid chromatography as described (Johnson et al. 2007). Secretion of Nec1 into culture supernatants was analyzed by growing strains in $25 \mathrm{ml}$ of TSB broth for $24 \mathrm{~h}$ and then testing filter-sterilized supernatants in a potato tuber disk assay as described previously (Joshi et al. 2007a).

\section{Bioinformatics analyses.}

DNA and protein sequences were routinely analyzed using Vector NTI 10.3.0 (Invitrogen Inc.). Predicted protein functions were assigned based on database similarity searches using BLASTP (National Center for Biotechnology Information). Protein domain analyses were performed using either the Pfam database (Finn et al. 2008) or the SEARCHPKS website in the case of the modular PKS proteins (Yadav et al. 2003). Protein sequence alignments were generated using either AlignX (Vector NTI 10.3.0) or ClustalX (Chenna et al. 2003) and phylogenetic analysis using the maximum likelihood method was performed using PhyML (Guindon and Gascuel 2003). 


\section{ACKNOWLEDGMENTS}

We thank K. Loeffler for photography, D. Gibson for assistance with the thaxtomin A analyses, and numerous other colleagues for providing Streptomyces strains used for detecting the $c f a 6$ and $c f a 7$ genes. This project was supported by the National Research Initiative of the United States Department of Agriculture Cooperative State Research, Education, and Extension Service, grant number 2008-35319-19202 (to R. Loria) and by the Robert A. Welch Foundation grant C-0729 (to R. J. Parry).

\section{LITERATURE CITED}

Anton, N., Santos-Aberturas, J., Mendes, M. V., Guerra, S. M., Martin, J. F., and Aparicio, J. F. 2007. PimM, a PAS domain positive regulator of pimaricin biosynthesis in Streptomyces natalensis. Microbiology 153:3174-3183.

Bell, K. S., Sebaihia, M., Pritchard, L., Holden, M. T., Hyman, L. J., Holeva, M. C., Thomson, N. R., Bentley, S. D., Churcher, L. J., Mungall, K., Atkin, R., Bason, N., Brooks, K., Chillingworth, T., Clark, K., Doggett, J., Fraser, A., Hance, Z., Hauser, H., Jagels, K., Moule, S., Norbertczak, H., Ormond, D., Price, C., Quail, M. A., Sanders, M., Walker, D., Whitehead, S., Salmond, G. P., Birch, P. R., Parkhill, J., and Toth, I. K. 2004. Genome sequence of the enterobacterial phytopathogen Erwinia carotovora subsp. atroseptica and characterization of virulence factors. Proc. Natl. Acad. Sci. U.S.A. 101:11105-11110.

Bender, C. L., Malvick, D. K., and Mitchell, R. E. 1989. Plasmid-mediated production of the phytotoxin coronatine in Pseudomonas syringae pv. tomato. J. Bacteriol. 171:807-812.

Bender, C., Rangaswamy, V., and Loper, J. 1999a. Polyketide Production by Plant-Associated Pseudomonads. Annu. Rev. Phytopathol. 37:175-196.

Bender, C. L., Alarcon-Chaidez, F., and Gross, D. C. 1999b. Pseudomonas syringae phytotoxins: Mode of action, regulation, and biosynthesis by peptide and polyketide synthetases. Microbiol. Mol. Biol. Rev. 63:266292.

Bentley, S. D., Chater, K. F., Cerdeno-Tarraga, A. M., Challis, G. L., Thomson, N. R., James, K. D., Harris, D. E., Quail, M. A., Kieser, H., Harper, D., Bateman, A., Brown, S., Chandra, G., Chen, C. W., Collins, M., Cronin, A., Fraser, A., Goble, A., Hidalgo, J., Hornsby, T., Howarth, S., Huang, C. H., Kieser, T., Larke, L., Murphy, L., Oliver, K., O’Neil, S., Rabbinowitsch, E., Rajandream, M. A., Rutherford, K., Rutter, S., Seeger, K., Saunders, D., Sharp, S., Squares, R., Squares, S., Taylor, K., Warren, T., Wietzorrek, A., Woodward, J., Barrell, B. G., Parkhill, J., and Hopwood, D. A. 2002. Complete genome sequence of the model actinomycete Streptomyces coelicolor A3(2). Nature 417:141-147.

Berdy, J. 2005. Bioactive microbial metabolites. J. Antibiot. (Tokyo) 58:126.

Bibb, M. J., White, J., Ward, J. M., and Janssen, G. R. 1994. The mRNA for the $23 \mathrm{~S}$ rRNA methylase encoded by the ermE gene of Saccharopolyspora erythraea is translated in the absence of a conventional ribosome-binding site. Mol. Microbiol. 14:533-545.

Bignell, D. R., Tahlan, K., Colvin, K. R., Jensen, S. E., and Leskiw, B. K. 2005. Expression of $c c a R$, encoding the positive activator of cephamycin $\mathrm{C}$ and clavulanic acid production in Streptomyces clavuligerus, is dependent on bldG. Antimicrob. Agents Chemother. 49:1529-1541.

Bukhalid, R. A., and Loria, R. 1997. Cloning and expression of a gene from Streptomyces scabies encoding a putative pathogenicity factor. J. Bacteriol. 179:7776-7783.

Bukhalid, R. A., Takeuchi, T., Labeda, D., and Loria, R. 2002. Horizontal transfer of the plant virulence gene, necl, and flanking sequences among genetically distinct Streptomyces strains in the Diastatochromogenes cluster. Appl. Environ. Microbiol. 68:738-744.

Butler, A. R., Bate, N., and Cundliffe, E. 1999. Impact of thioesterase activity on tylosin biosynthesis in Streptomyces fradiae. Chem. Biol. 6:287-292.

Challis, G. L. 2008. Mining microbial genomes for new natural products and biosynthetic pathways. Microbiology 154:1555-1569.

Chan, Y. A., Podevels, A. M., Kevany, B. M., and Thomas, M. G. 2009. Biosynthesis of polyketide synthase extender units. Nat. Prod. Rep. 26:90-114.

Chater, K. F., and Chandra, G. 2008. The use of the rare UUA codon to define "expression space" for genes involved in secondary metabolism, development and environmental adaptation in Streptomyces. J. Microbiol. 46:1-11.

Chenna, R., Sugawara, H., Koike, T., Lopez, R., Gibson, T. J., Higgins, D. G., and Thompson, J. D. 2003. Multiple sequence alignment with the Clustal series of programs. Nucleic Acids Res. 31:3497-3500.

Donadio, S., and Katz, L. 1992. Organization of the enzymatic domains in the multifunctional polyketide synthase involved in erythromycin formation in Saccharopolyspora erythraea. Gene 111:51-60.
Elliot, M. A., Buttner, M. J., and Nodwell, J. R. 2008. Multicellular development in Streptomyces. Pages 419-438 in: Myxobacteria: Multicellularity and Differentiation. D. E. Whitworth, ed. ASM Press, Washington, DC.

Finn, R. D., Tate, J., Mistry, J., Coggill, P. C., Sammut, S. J., Hotz, H. R., Ceric, G., Forslund, K., Eddy, S. R., Sonnhammer, E. L., and Bateman, A. 2008. The Pfam protein families database. Nucleic Acids Res. 36:D281-288.

Fry, B., and Loria, R. 2002. Thaxtomin A: Evidence for a plant cell wall target. Physiol. Mol. Plant Pathol. 60:1-8.

Glazebrook, J. 2005. Contrasting mechanisms of defense against biotrophic and necrotrophic pathogens. Annu. Rev. Phytopathol. 43:205-227.

Gnanamanickam, S. S., Starratt, A. N., and Ward, E. W. B. 1982. Coronatine production in vitro and in vivo and its relation to symptom development in bacterial blight of soybean. Can. J. Bot. 60:645-650.

Guindon, S., and Gascuel, O. 2003. A simple, fast, and accurate algorithm to estimate large phylogenies by maximum likelihood. Syst. Biol. 52:696-704.

Gust, B., Challis, G. L., Fowler, K., Kieser, T., and Chater, K. F. 2003. PCR-targeted Streptomyces gene replacement identifies a protein domain needed for biosynthesis of the sesquiterpene soil odor geosmin Proc. Natl. Acad. Sci. U.S.A. 100:1541-1546.

Healy, F. G., Wach, M., Krasnoff, S. B., Gibson, D. M., and Loria, R. 2000. The $t x t A B$ genes of the plant pathogen Streptomyces acidiscabies encode a peptide synthetase required for phytotoxin thaxtomin A production and pathogenicity. Mol. Microbiol. 38:794-804.

Hefti, M. H., Francoijs, K. J., de Vries, S. C., Dixon, R., and Vervoort, J. 2004. The PAS fold. A redefinition of the PAS domain based upon structural prediction. Eur. J. Biochem. 271:1198-1208.

Hopwood, D. A., Bibb, M. J., Chater, K. F., Kieser, T., Bruton, C. J., Kieser, H. M., Lydiate, D. J., Smith, C. P., Ward, J. M., and Schrempf, H. 1985. Genetic Manipulation of Streptomyces: A Laboratory Manual. The John Innes Foundation, Norwich, U.K.

Ikeda, H., Ishikawa, J., Hanamoto, A., Shinose, M., Kikuchi, H., Shiba, T., Sakaki, Y., Hattori, M., and Omura, S. 2003. Complete genome sequence and comparative analysis of the industrial microorganism Streptomyces avermitilis. Nat. Biotechnol. 21:526-531.

Johnson, E. G., Joshi, M. V., Gibson, D. M., and Loria, R. 2007. Cello-oligosaccharides released from host plants induce pathogenicity in scabcausing Streptomyces species. Physiol. Mol. Plant Pathol. 71:18-25.

Johnson, E. G., Krasnoff, S. B., Bignell, D. R., Chung, W. C., Tao, T., Parry, R. J., Loria, R., and Gibson, D. M. 2009. 4-Nitrotryptophan is a substrate for the non-ribosomal peptide synthetase TxtB in the thaxtomin A biosynthetic pathway. Mol. Microbiol. 73:409-418.

Joshi, M. V., and Loria, R. 2007. Streptomyces turgidiscabies possesses a functional cytokinin biosynthetic pathway and produces leafy galls. Mol. Plant-Microbe Interact. 20:751-758.

Joshi, M., Rong, X., Moll, S., Kers, J., Franco, C., and Loria, R. 2007a. Streptomyces turgidiscabies secretes a novel virulence protein, Nec1, which facilitates infection. Mol. Plant-Microbe Interact. 20:599-608.

Joshi, M. V., Bignell, D. R., Johnson, E. G., Sparks, J. P., Gibson, D. M., and Loria, R. 2007b. The AraC/XylS regulator TxtR modulates thaxtomin biosynthesis and virulence in Streptomyces scabies. Mol. Microbiol. 66:633-642.

Katsir, L., Chung, H. S., Koo, A. J., and Howe, G. A. 2008a. Jasmonate signaling: A conserved mechanism of hormone sensing. Curr. Opin. Plant Biol. 11:428-435.

Katsir, L., Schilmiller, A. L., Staswick, P. E., He, S. Y., and Howe, G. A. 2008b. COI1 is a critical component of a receptor for jasmonate and the bacterial virulence factor coronatine. Proc. Natl. Acad. Sci. U.S.A. 105:7100-7105.

Katz, L. 2009. The DEBS paradigm for type I modular polyketide synthases and beyond. Methods Enzymol. 459:113-142.

Kers, J. A., Cameron, K. D., Joshi, M. V., Bukhalid, R. A., Morello, J. E., Wach, M. J., Gibson, D. M., and Loria, R. 2005. A large, mobile pathogenicity island confers plant pathogenicity on Streptomyces species. Mol. Microbiol. 55:1025-1033.

Kieser, T., Bibb, M. J., Buttner, M. J., Chater, K. F., and Hopwood, D. A. 2000. Practical Streptomyces Genetics. The John Innes Foundation, Norwich, U.K.

King, R. R., and Calhoun, L. A. 2009. The thaxtomin phytotoxins: Sources, synthesis, biosynthesis, biotransformation and biological activity. Phytochemistry 70:833-841.

Lawlor, E. J., Baylis, H. A., and Chater, K. F. 1987. Pleiotropic morphological and antibiotic deficiencies result from mutations in a gene encoding a tRNA-like product in Streptomyces coelicolor A3(2). Genes Dev. 1:1305-1310.

Leskiw, B. K., Lawlor, E. J., Fernandez-Abalos, J. M., and Chater, K. F. 1991. TTA codons in some genes prevent their expression in a class of developmental, antibiotic-negative, Streptomyces mutants. Proc. Natl. 
Acad. Sci. U.S.A. 88:2461-2465.

Liyanage, H., Palmer, D. A., Ullrich, M., and Bender, C. L. 1995. Characterization and transcriptional analysis of the gene cluster for coronafacic acid, the polyketide component of the phytotoxin coronatine. Appl. Environ. Microbiol. 61:3843-3848.

Loria, R., Bukhalid, R. A., Creath, R. A., Leiner, R. H., Olivier, M., and Steffens, J. C. 1995. Differential production of thaxtomins by pathogenic Streptomyces species in vitro. Phytopathology 85:537-541.

Loria, R., Kers, J., and Joshi, M. 2006. Evolution of plant pathogenicity in Streptomyces. Annu. Rev. Phytopathol. 44:469-487.

Loria, R., Bignell, D. R., Moll, S., Huguet-Tapia, J. C., Joshi, M. V., Johnson, E. G., Seipke, R. F., and Gibson, D. M. 2008. Thaxtomin biosynthesis: The path to plant pathogenicity in the genus Streptomyces. Antonie Leeuwenhoek 94:3-10

MacNeil, D. J., Gewain, K. M., Ruby, C. L., Dezeny, G., Gibbons, P. H., and MacNeil, T. 1992. Analysis of Streptomyces avermitilis genes required for avermectin biosynthesis utilizing a novel integrative vector. Gene 111:61-68.

Melotto, M., Underwood, W., Koczan, J., Nomura, K., and He, S. Y. 2006. Plant stomata function in innate immunity against bacterial invasion. Cell 126:969-980.

Melotto, M., Mecey, C., Niu, Y., Chung, H. S., Katsir, L., Yao, J., Zeng, W., Thines, B., Staswick, P., Browse, J., Howe, G. A., and He, S. Y. 2008a. A critical role of two positively charged amino acids in the Jas motif of Arabidopsis JAZ proteins in mediating coronatine- and jasmonoyl isoleucine-dependent interactions with the COI1 F-box protein. Plant J. 55:979-988.

Melotto, M., Underwood, W., and He, S.Y. 2008b. Role of stomata in plant innate immunity and foliar bacterial diseases. Annu. Rev. Phytopathol. 46:101-122.

Murashige, T., and Skoog, F. 1962. A revised medium for rapid growth and bioassays with tobacco tissue cultures. Physiol. Plant. 15:473-497.

Ohnishi, Y., Ishikawa, J., Hara, H., Suzuki, H., Ikenoya, M., Ikeda, H., Yamashita, A., Hattori, M., and Horinouchi, S. 2008. Genome sequence of the streptomycin-producing microorganism Streptomyces griseus IFO 13350. J. Bacteriol. 190:4050-4060.

Rangaswamy, V., Ullrich, M., Jones, W., Mitchell, R., Parry, R., Reynolds, P., and Bender, C. L. 1997. Expression and analysis of coronafacate ligase, a thermoregulated gene required for production of the phytotoxin coronatine in Pseudomonas syringae. FEMS (Fed. Eur. Microbiol. Soc.) Microbiol. Lett. 154:65-72.

Rangaswamy, V., Jiralerspong, S., Parry, R., and Bender, C. L. 1998. Biosynthesis of the Pseudomonas polyketide coronafacic acid requires monofunctional and multifunctional polyketide synthase proteins. Proc. Natl. Acad. Sci. U.S.A. 95:15469-15474.

Sakai, R., Nishiyama, K., Ichihara, A., Shiraishi, K., and Sakamura, S. 1979. Studies on the mechanism of physiological activity of coronatine.
Effect of coronatine on cell wall extensibility and expansion of potato tuber tissue. Ann. Phytopathol. Soc. Jpn. 45:645-653.

Sambrook, J., Fritsch, E. F., and Maniatis, T. 1989. Molecular Cloning: A Laboratory Manual. Cold Spring Harbor Laboratory Press, Cold Spring Harbor, NY, U.S.A.

Scheible, W.-R., Fry, B., Kochevenko, A., Schindelasch, D., Zimmerli, L., Somerville, S., Loria, R., and Somerville, C. R. 2003. An Arabidopsis mutant resistant to thaxtomin A, a cellulose synthesis inhibitor from Streptomyces species. Plant Cell 15:1781-1794.

Seipke, R. F., and Loria, R. 2008. Streptomyces scabies 87-22 possesses a functional tomatinase. J. Bacteriol. 190:7684-7692.

Sekurova, O. N., Brautaset, T., Sletta, H., Borgos, S. E., Jakobsen, M. O., Ellingsen, T. E., Strom, A. R., Valla, S., and Zotchev, S. B. 2004. In vivo analysis of the regulatory genes in the nystatin biosynthetic gene cluster of Streptomyces noursei ATCC 11455 reveals their differential control over antibiotic biosynthesis. J. Bacteriol. 186:1345-1354.

Smith, L., Hong, H., Spencer, J. B., and Leadlay, P. F. 2008. Analysis of specific mutants in the lasalocid gene cluster: Evidence for enzymatic catalysis of a disfavoured polyether ring closure. Chembiochemistry 9:2967-2975.

Taylor, B. L., and Zhulin, I. B. 1999. PAS domains: Internal sensors of oxygen, redox potential, and light. Microbiol. Mol. Biol. Rev. 63:479506.

Thines, B., Katsir, L., Melotto, M., Niu, Y., Mandaokar, A., Liu, G., Nomura, K., He, S. Y., Howe, G. A., and Browse, J. 2007. JAZ repressor proteins are targets of the $\mathrm{SCF}(\mathrm{COI} 1)$ complex during jasmonate signalling. Nature 448:661-665.

Volksch, B., Bublitz, F., and Fritsche, W. 1989. Coronatine production by Pseudomonas syringae pathovars: Screening method and capacity of product formation. J. Basic Microbiol. 29:463-468.

Wright, F., and Bibb, M. J. 1992. Codon usage in the G+C-rich Streptomyces genome. Gene 113:55-65.

Yadav, G., Gokhale, R. S., and Mohanty, D. 2003. SEARCHPKS: A program for detection and analysis of polyketide synthase domains. $\mathrm{Nu}$ cleic Acids Res. 31:3654-3658

Zhao, B., and Waterman, M. R. 2007. Novel properties of P450s in Streptomyces coelicolor. Drug Metab. Rev. 39:343-352.

\section{AUTHOR-RECOMMENDED INTERNET RESOURCES}

The National Center for Biotechnology Information genome project database: www.ncbi.nlm.nih.gov/genomes/lproks.cgi

SEARCKPKS (A Program for Detection and Analysis of Polyketide Synthase Domains) website: www.nii.res.in/searchpks.html.

The Wellcome Trust Sanger Institute Streptomyces scabies webpage: www.sanger.ac.uk/Projects/S_scabies 